University of Louisville

ThinkIR: The University of Louisville's Institutional Repository

Electronic Theses and Dissertations

8-2013

\title{
Enhanced penetration of lipid functionalized nanoparticles in 3D cell cultures.
}

Christopher Gene England 1988-

University of Louisville

Follow this and additional works at: https://ir.library.louisville.edu/etd

\section{Recommended Citation}

England, Christopher Gene 1988-, "Enhanced penetration of lipid functionalized nanoparticles in 3D cell cultures." (2013). Electronic Theses and Dissertations. Paper 406.

https://doi.org/10.18297/etd/406

This Master's Thesis is brought to you for free and open access by ThinkIR: The University of Louisville's Institutional Repository. It has been accepted for inclusion in Electronic Theses and Dissertations by an authorized administrator of ThinkIR: The University of Louisville's Institutional Repository. This title appears here courtesy of the author, who has retained all other copyrights. For more information, please contact thinkir@louisville.edu. 


\title{
ENHANCED PENETRATION OF LIPID FUNCTIONALIZED NANOPARTICLES IN 3D CELL
}

\section{CULTURES}

\author{
By
}

Christopher Gene England

B.S., Bellarmine University, 2011

\author{
A Thesis \\ Submitted to the Faculty of the \\ School of Medicine of the University of Louisville \\ In Partial Fulfillment of the Requirements \\ For the Degree of
}

Masters of Science

Department of Pharmacology and Toxicology

University of Louisville

Louisville, KY

August 2013 



\section{ENHANCED PENETRATION OF LIPID FUNCTIONALIZED NANOPARTICLES IN 3D CELL CULTURES}

By

Christopher England

A Thesis Approved on

June 21, 2013

By the following Thesis Committee:

Hermann Frieboes, PhD- Thesis Director

Lacey McNally, PhD

Brian Ceresa, $\mathrm{PhD}$

Michele Kosiewicz, $\mathrm{PhD}$ 


\section{ACKNOWLEDGMENTS}

I would like to thank my primary mentor, Dr. Hermann Frieboes, for his guidance during this period. I would like to acknowledge Dr. Andre Gobin for his help during this project. I would like to thank the committee members who agreed to assist in my graduate education. The University of Louisville, IPIBS, Dept. of Pharmacology and Toxicology, and Dept. of Bioengineering has provided the necessary funds and equipment needed for completing this project, thus I owe much gratitude to these entities. 


\title{
ABSTRACT \\ ENHANCED PENETRATION OF LIPID FUNCTIONALIZED NANOPARTICLES IN 3D CELL CULTURES
}

\author{
Christopher G. England
}

June 21, 2013

Nanoparticle-based systems can alleviate systemic toxicity via surface functionalization to promote tissuespecific targeting as well as passive targeting abilities [1], such as the enhanced permeation and retention effect (EPR) [2]. The transport of nanoparticles is limited in hypoxic tumor regions due to the typically impaired tumor vasculature. To enhance diffusion of nanotherapeutics within tumor tissue; functionalized citrate gold nanoparticles and silica gold nanoshells with surface modifications of phosphatidylcholine (PC) and high density lipoprotein (HDL) were synthesized. 3D cell cultures were used as a representative model of portions of hypoxic tissue in liver, lung, and pancreatic solid tumors. Our results indicate that two layered silica gold nanoshells (surface modifications of -thiol and PC) permit enhanced accumulate compared to PEGylated nanoparticles. The addition of HDL for the smaller, citrate gold nanoparticles as a third external layer provided enriched accumulation compared to PEGylated nanoparticles. In conclusion, nanoparticles functionalized with PC and HDL show superior accumulation in avascular tumor tissue in comparison to previously designed PEGylated nanoparticles. 


\section{TABLE OF CONTENTS}

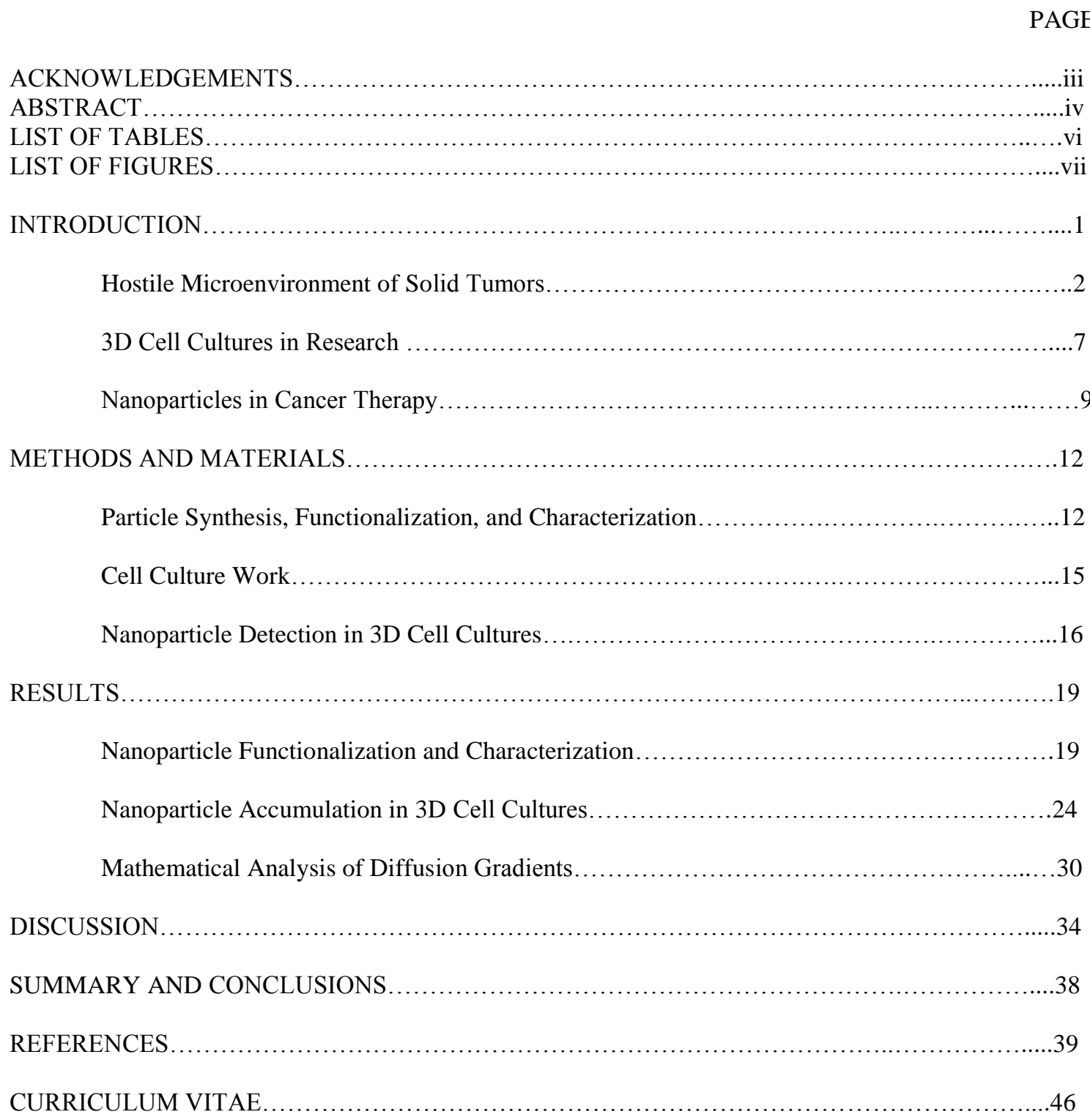




\section{LIST OF TABLES}

TABLE

PAGE

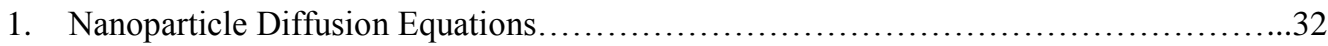

2. Estimated Number of Nanoparticles in Outer $50 \mu \mathrm{m}$ Section of Spheroid..................33 


\section{LIST OF FIGURES}

$\begin{array}{ll}\text { FIGURE } & \text { PAGE }\end{array}$

1. Histology of Normal and Cancerous Pancreatic Tissue.......................................

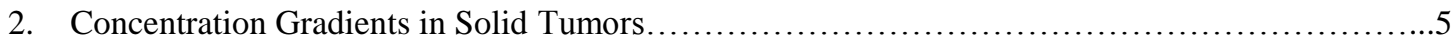

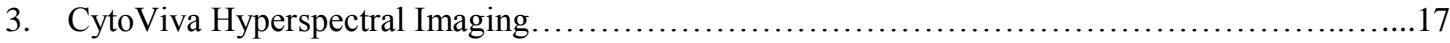

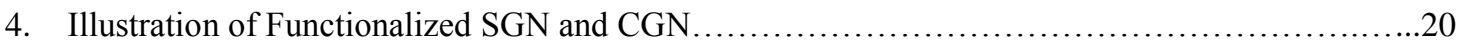

5. Characterization of SGC and CGN using UV-Vis Spectroscopy and Zeta Potential Analysis.......21

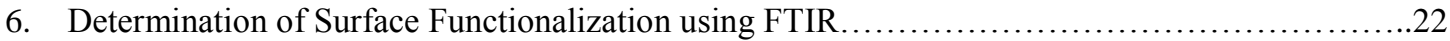

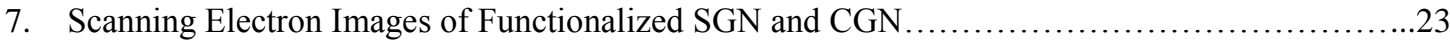

8. Detection of Nanoparticle Presence in 3D Cell Cultures through Silver Staining...................24

9. ROI Intensity Comparison between 3D Cell Culture Periphery and Inner Region................26

10. Detection of Nanoparticles within 3D Cell Cultures using Dark Field Microscopy .................27

11. Nanoparticle Diffusion into Inner Regions of 3D Cell Cultures....................................38

12. Illustration of Tumor Spheroid Nanoparticle Diffusion........................................ 


\section{INTRODUCTION}

The microenvironment within cancerous tissue is a critical barrier leading to the unsuccessful treatment of most solid tumors. Severity and lethality of many cancer forms have been decreasing during the last fifty years due to extraordinary breakthroughs in therapeutic treatment strategies. On the contrary, solid tumors of the lung, pancreas, and liver remain three of the most lethal forms of cancer in the United States [3]. Current functional chemotherapeutics and drug delivery mechanisms often fail to cure patients. For this reason, novel treatment modalities are critically needed in the clinic, promoting the extension of five-year survival rates along with enhanced quality of life. In the United States, cancer is now the leading cause of death claiming the lives of 1,600 people per day [3], illustrating the dire need for supplemented or modified treatment strategies to promote survival in patients. This study examines the penetration and diffusion capabilities of lipid functionalized nanoparticles as a potential methodology for enhancing the delivery of vital chemotherapeutic agents deeper into solid tumor tissue. This enhanced delivery will promote therapeutic levels of drug exposure to portions of tumor normally experiencing sub-optimal chemotherapeutic levels. This study examines the diffusion capabilities of lipid functionalized nanoparticles, providing the necessary foundation for future studies in drug delivery. To enhance tumor uptake of nanoparticles, nanoparticle were functionalized with either two- or three layers consisting of phosphatidylcholine and HDL. 3D cell cultures of A549 (human lung carcinoma), S2VP10 (human pancreatic adenocarcinoma), and HepG2 (liver hepatocellular carcinoma) were used to analyze the penetration and diffusion capabilities of lipid-functionalized nanoparticles within hypoxic portions of avascular tumor tissue. 


\section{HOSTILE MICROENVIRONMENT OF SOLID TUMORS}

The human body is constructed ensuring all normal cells are located within a few cell diameters of blood supply. This promotes normal cellular function for each of the $\sim 10^{13}$ cell found in each person $[4,5]$. While this complex system holds true for normal tissue, the ideology collapses when cellular proliferation increases at higher rates than the endothelial cells that form blood capillaries, as in most solid cancerous

tumors $[5,6]$. This enhanced proliferating of cells and decreased apoptotic rate eventually reduces vascular density, leading to areas of tumor experiencing hypoxia, poor perfusion, and high permeability [7, 8].

These hypoxic portions of tumor tissue lacking the needed $\mathrm{pO}_{2}$ are normally formed when cells are located $\sim 100-200 \mu \mathrm{m}$ from the nearest blood vessel, yet this can vary based upon the type of solid tumor [5, 9]. Other than hypoxia, the surrounding tissue is also subjected to increased interstitial fluid pressure (IFP) from the irregular vasculature and lack of lymphatic vessels, along with decreased extracellular pH due to the buildup of metabolic waste products such as lactic and carbonic acid [5, 10]. For these reasons, the hostility of the tumor microenvironment is a strong determinant of successful clinical treatment and a critical barrier that must be addressed in improving current treatment methods. 

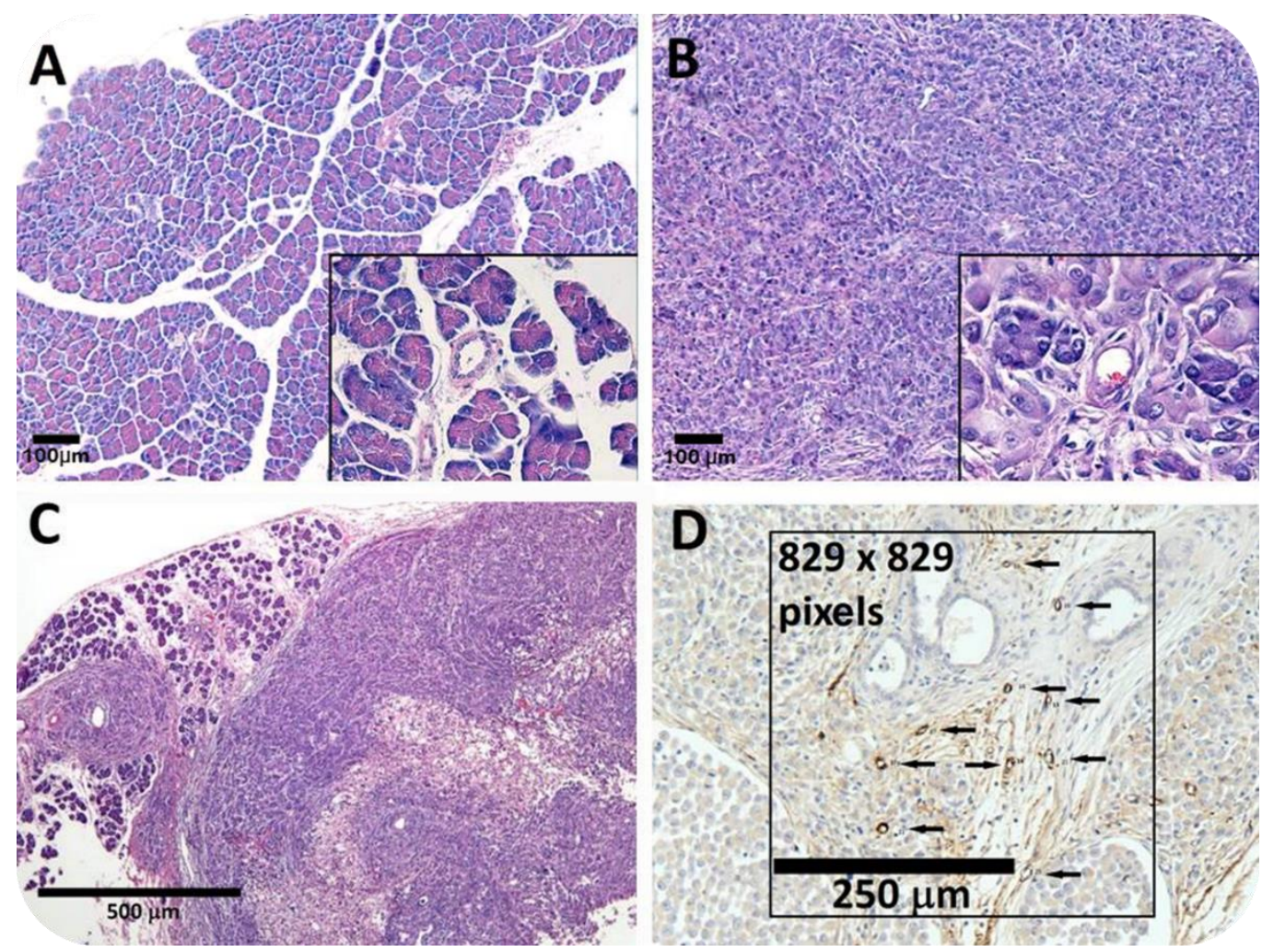

Figure 1: Histology of Normal and Cancerous Pancreatic Tissue. SCID mice injected with S2VP10L were euthanized and organs were retrieved and sectioned for histological analysis. (A) Normal pancreatic tissue illustrating the organized vasculature providing the necessary oxygen and nutrients to the surrounding tissue composed of serous acini and zymogenic cells, along with pancreatic islets and specialized ducts. (B) Cancerous pancreatic tissue depicts a disorganized array of cells with a lack of blood vessels supporting the vast amount of tissue. For this entire portion of tissue, there is only a few blood vessels supplying nutrients and oxygen. (C) Depiction of both non-cancerous and cancerous tissue shows the lack of cellular organization from the normal tissue (left) to the cancerous tissue (right), with necrosis portions of tissue forming from lack of oxygen. (D) The CD17 stain intensifies the color surrounding vasculature with the arrows depicting blood vessels found in the pancreatic tissue [11].

Generally, there are three accepted hypotheses denoting why cells distant from vasculature may acquire increased resistance to conventional chemotherapeutic regimens. First, cells residing within hypoxic microenvironments normally alter their metabolic activity to promote survival while experiencing deficient concentrations of oxygen and other nutrients [12-14]. This alteration in metabolic activity may 
lead to cellular quiescence, in which cell ceases division and enters a period of resting [5]. During the $\mathrm{G}_{0}$ portion of the cell cycle, cell-cycle specific chemotherapeutics designed for instigating selective toxicity during certain phases of the cell cycle such as the S-, M- or G-phase will not provide therapeutic benefits $[15,16]$.

Secondly, hypoxic portions of tumor also experience other harsh conditions such as ischemia (lack of nutrients) and increased extracellular $\mathrm{pH}$ levels leading to acidic microenvironments [5]. Drug efficacy can be effected by factors such as $\mathrm{pH}$, which can alter the ionization of some drugs possibly causing drug-inactivation [15]. Lastly, the filamentous extracellular matrix (ECM) and other components of the hostile microenvironment may hinder overall delivery of chemotherapy drugs (including nanoparticles) to hypoxic portions of solid tumor $[5,6,17]$. This decreased accumulation of drugs (and nanoparticles) within the solid tumor leads to suboptimal chemotherapeutic exposure not reaching the minimum inhibitory concentration needed to produce a therapeutic response $[2,18]$. Overall, the concentration gradients of oxygen and other nutrients, as illustrated in Figure 2, must be considered when designing novel chemotherapeutic drugs or treatment modalities, including nanoparticles, for possible clinical applications. 


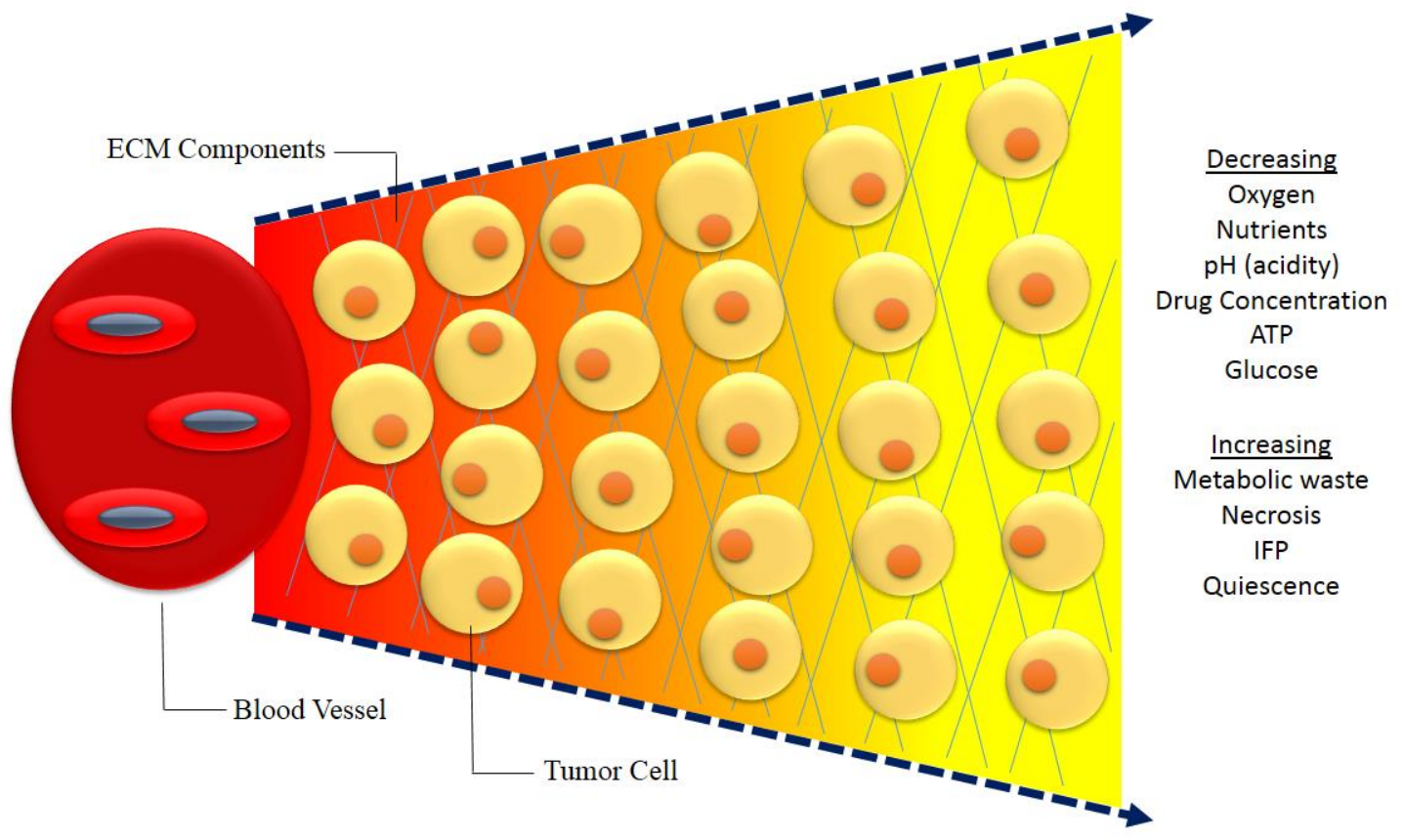

Figure 2: Concentration Gradients Found in Solid Tumors. The microenvironment found in solid tumors is different from normal tissue. Cells distant from vasculature receive decreased amounts of oxygen, nutrients, drug availability, energy, and $\mathrm{pH}$ (promoting an acidic environment). These distant cells can experience hypoxia leading to cellular quiescence, along with tissue necrosis due to an increased interstitial fluid pressure and other factors [5]. Illustration created by author.

The tumor microenvironment is used for the exchange of information in normal and cancerous tissues through cell-cell contacts, cytokines, and the ECM [19]. The tumor microenvironment is composed of multiple components including immune cells, along with stromal fibroblasts and epithelial cells providing the structural scaffolding of the tissue [19]. The variable combination of numerous cell types (such as immune cells, fibroblasts, and endothelial cells) better depict the tissue found in solid tumors and the microenvironment within this tissue [20]. Drug efficacy testing is normally completed using monolayer cell cultures because of wide-spread availability and ease of use, yet monolayer cell cultures do not portray the same type of tissue found in vivo due to the lack of ECM components, diffusion gradients of nutrients, and various cell types [21]. In conclusion, the hostile microenvironment, along with irregular vasculature, 
of solid tumors hinder the transport of drug and other molecules (such as nanoparticles) within tumor tissue causing suboptimal chemotherapeutic exposure and therapeutic failure $[2,7,20]$. 


\section{D CELL CULTURES IN RESEARCH}

3D cell cultures provide additional spatial information for studying the microenvironment of solid tumors as they have the ability to form ECM components along with realistic morphology similar to that found in vivo [22, 23]. Since the growth and treatment response of solid tumors is critically influenced by their microenvironment, this interaction is crucial for studying parameters such as hypoxia and drug or nanoparticle delivery in 3-dimensions [24]. Monolayer cell cultures have been the most widely employed method of accessing drug efficacy and toxicity in vitro [22, 25-29]. The animal model has the advantage of reproducing the clinical effects, yet remains costly and time-consuming. 3D cell cultures provide a unique advantage over in vivo models by eliminating many of the complicating factors such as immune cell interaction, first-pass effect, and urinary excretion [30]. 3D cell cultures promote the development of an ECM, tight junctions between the epithelia cells, gradients of nutrients concentration, and gradients of cell proliferation from the exterior to the interior of the tumor $[5,28,31]$. These cell cultures can produce

spheroids up to $1 \mathrm{~mm}$ in size with larger spheroids becoming hypoxic with necrotic cores, qualities similar to those found in solid tumors $[5,9]$.

While monolayer cell cultures have been used greatly in the past, the advantages to using 3D cell are clearly visible and supported by research. Many groups have studies the similarities between growing traditional monolayer 2D cell cultures in comparison to the 3D method. For example, scientists were able to determine that transformed lung cells grown in 3D conditions displayed cellular markers more closely resembled to the animal model compared to the traditional monolayer cell cultures. This study also indicated that cellular differentiation of 3D cell cultures were more closely related to animal model as compared to monolayer cell cultures [32,33]. Experiments with 3D cell cultures have helped to analyze the effect of physical barriers on optimal drug delivery in comparison to monolayer studies [34-36], e.g., the impact of the extracellular matrix was studied by Goodman et al. who demonstrated an increased penetration of nanoparticles treated with collagenase in 3D cell cultures [36].

Overall, there are four crucial features of 3D cell cultures illustrating their superiority in comparison to monolayer cell cultures. The first feature is the ability of 3D cell cultures to reestablish 
morphological, functional, and mass transport features of the corresponding tissue found in vivo [21, 37, 38]. It was shown that 3D cell cultures can maintain some of the differentiation patterns found in animals models for weeks [37]. These features are created and maintained by the tumor cell-derived ECM along with the cellular interactions, e.g. cell-cell and cell-matrix interactions [21]. Both of these interactions are absent from monolayer cell cultures giving rise to the possibility of using $3 \mathrm{D}$ cell cultures for studies involving drug penetration in tumors, binding of certain biological agents, and drug bioactivity. Secondly, the 3D cell cultures can mimic many characteristics of the avascular tumor nodules, micro-metastases, or intravascular regions of large solid tumors [21, 37]. 3D cell cultures form gradients in which proliferating cells are found toward the periphery with quiescent cells found in the center. This suggests that cells experiencing cell-cycle arrest will be further into the tumor core exhibiting necrosis [21]. The necrotic cells are located in spheroids possessing a diameter greater than $500 \mu \mathrm{m}$ allowing scientists to study solid tumor necrosis, hypoxia, and ischemia [21, 37, 39].

Next, the well-defined spherical geometry of the 3D cell cultures provides an easy representative model that can be expressed mathematically for computational analysis. The unique structure produced by 3D cell cultures also allows for direct comparison of structure to function, allowing for studies of drug response that can be localized within the tumor microenvironment $[6,37]$. In reality, diffusion gradients of various components (nutrients, drugs, nanoparticles, etc.) can be studied using 3D cell cultures [6, 21]. Lastly, 3D cell cultures provide the unique opportunity for co-culturing of various cell types due to clustering effects [40, 41]. For example, scientists have shown that co-cultures containing A549 cancer cells, THP-1 macrophages, HMC-1 mast cells, and EAHY926 endothelial cells, more closely mimicked the actual tumor experience found in vivo compared to the A549 single cell cultures [40]. Local effects of differential cells can cause catastrophic differences in therapy response providing vital details about interactions between the immune system and cancerous tumors [40, 42]. It is important to understand the solid tumor on a larger scale rather than one type of cell. While 3D cell cultures have great benefits, this system also has downfalls. For example, 3D cell cultures require costly culturing plates and equipment to form the culture. In conclusion, 3D cell cultures provide a more realistic approach for studying nanoparticle (or drug) penetration and diffusion within tissue. 


\section{NANOPARTICLES IN CANCER THERAPY}

Advances in nanotechnology have provided enhanced targeting and efficient transport of chemotherapeutic drugs into solid tumors. Studies have shown that nanotherapeutics may provide new hope for patients due to their ability to deliver an increased concentration of drug to tumor tissue that is protected from environmental degradation through active targeting of specific receptors up-regulated in cancerous tissue. Nanotherapeutics also provide the ability to bypass resistance mechanisms like MDR (such as P-glycoprotein), while also avoiding immune cells of the reticuloendothelial system (RES) [4347].

Since traditional chemotherapeutics may be unable to bypass the physical barriers and resistance mechanisms offered by the microenvironment and cells in solid tumors, there is a critical need for new methodologies. There are several nano-based therapies in clinical use or in clinical trials including FDA approved Abraxane ${ }^{\circledR}$ for the treatment of lung cancer [48], the investigational lipid nanoparticles containing siRNA ALN-VSP for the treatment of liver cancer [49], and multiple polymeric nanoparticles containing platinum drugs for the treatment of multiple cancer types including pancreatic cancer [49]. The FDA approved drug Doxil $®$ is a PEGylated liposomal carrier encapsulating doxorubicin that is used for ovarian cancer and multiple myeloma $[48,50]$.

Cancer specificity can be altered through the functionalization process of nanoparticle synthesis, yielding novel treatment modalities for liver, lung, and pancreatic cancer. The addition of targeting ligands (boronic acid proteins, galactosamine, glycyrrhetinic acid, galactose, lactosyl-norcantharidin, bovine serum albumin, monoclonal anti-MT1-MMP antibody, anti-VEGF, etc. ) to the surface of nanoparticle have enhanced the delivery of drugs such as docetaxel, oridonin, sodium ferulate, doxorubicin, siRNAs, 5fluorouracil, and paclitaxel to the liver [10,23, 51-63]. These studies have shown the possibility of using specific ligands to promote active targeting to hepatocytes, while avoiding surrounding healthy tissue. While liver and pancreatic cancer chemotherapeutics must be given through intravenous injection (I.V.), the inhalation route of administration in lung cancer can provide both localized and systemic actions. Inhalable nanoparticle powders (such as lactose and chitosan-PLGA) containing therapeutic agents such as 
doxorubicin, calcitonin, itraconazole, and rifampicin have shown localized benefit in the treatment of lung cancer [64-68]. While beneficial, there modified drugs have come with adverse effects through translocation of the nanoparticles from the lungs to other remote organs $[64,69-75]$. The I.V. route of administration has shown promises in the treatment of lung cancer with active targeting to the lung by: targeting telomerase activity through potent telomerase inhibitors [76, 77], delivery of siRNA to knockdown oncogenes such as mouse double minute 2 (MDM2) [78], enhancing gene delivery through using a bioadhesive stabilizer (Carbopol 940) or p53 [79, 80], and specifically targeting the EGFR overexpression for chemotherapeutic delivery [81-83].

So far, the delivery of chemotherapeutics to cancerous cells of the pancreas has failed miserably with five year survival rates of only $6 \%$ [3]. Nano-based treatments for pancreatic cancer aim to deliver chemotherapeutic agents such as gemcitabine, cisplatin, tetraiodothyroacetic acid, gambogic acid, and metformin [84-87], using targeting ligands to entities such as integrin $\alpha \mathrm{V} \beta 3$ receptor [88], matrix metalloproteinases [89], Herceptin (HER2) [90], EGFR [91], and fucosyltransferases [86]. While these studies have shown successful treatment of pancreatic cancer in vitro and in vivo, delivery of an effective dose of nanoparticles in human trials still remains deficient.

Passive and active targeting of nanoparticles promote increased accumulation in tumor tissue due to the leaky tumor vasculature, the enhanced permeability and retention (EPR) effect, and selectivity for up-regulated receptors such as HDL [92-95]. In general, multiple studies have analyzed the possible toxicity from the accumulation of gold, yet the studies did not show any form of systemic toxicity [96, 97]. Through the process of functionalization, nanoparticles can be modified to promote active targeting and increase circulation time allowing for more uniform drug delivery [98-100]. The addition of surface modifications to nanoparticles can alter factors such as surface charge, circulation time, active targeting abilities, and retention effects [101]. Positively charged nanoparticles tend to improve the payload of drug delivered to cells while negatively charged nanoparticles seem to diffuse more quickly through the tissue [102]. There are various surface modifications that can be appended to form new variants of nanoparticles. The most common surface modification is PEGylation or the addition of poly(ethylene)glycol (PEG) [98100]. The addition of PEG promotes steric stabilization while hindering interaction with immune system cells of the mononuclear phagocyte system (MPS) $[43,98,101]$. The addition of phosphatidylcholine (PC) 
onto the surface of gold nanorods was shown to decrease the amount of particle agglomeration as well as toxic effects [103]. The addition of high-density lipo-protein (HDL) has been studied due to an enhanced HDL-cholesterol uptake in many human cancers [104, 105].

Once small nanoparticles extravasate from the tumor vasculature, their range of diffusion is a critical determinant of successful therapy. Wong et al. have demonstrated diffusion of nanoparticles in collagen gel [2], and Goodman et al. used fluorescent staining to determine approximate nanoparticle concentration in 3D cell culture [36]. Particle accumulation was shown to be size dependent by Huang et al. and others suggesting that particles $\sim 20 \mathrm{~nm}$ or smaller had superior penetration abilities compared to larger particles [106-108]. Smaller particles $(<50 \mathrm{~nm})$ are not as useful for drug delivery as compared to larger nanoparticles due to their small payloads and low EPR effect [106]. Huang et al. also demonstrated that $2 \mathrm{~nm}$ nanoparticles were able to reach inner portions of tumor spheroids better than larger particles, which was also confirmed in vivo [106]. Other groups such as Cabral et al. showed that larger polymeric micelles (>200 nm) were only able to diffuse within hyper-vascularized tumors, while only sub-100 nm particles were able to penetrate and diffuse through tumors experiencing hypoxia (hypo-vascularized) [108].

In this study we examine the uptake of functionalized citrate gold nanoparticles (CGN) along with silica gold nanoshells (SGN) in 3D cell cultures. Performance of nanoparticles was evaluated in three different cancer cell lines including A549, S2VP10, and HepG2. The surfaces of CGN and SGN were functionalized through a two- or three-layering process to optimize uptake into tumor tissue. The two- layer particles were synthesized with an inner layer of -thiol and an outer layer of PC. In order to further optimize tumor uptake, active targeting was promoted by adding HDL on the exterior of the PC layer creating the three- layered nanoparticles. The uptake and distribution of these nanoparticles in 3D cell was compared with previously designed PEGylated nanoparticles. 


\title{
METHODS
}

\section{PARTICLE SYNTHESIS, FUNCTIONALIZATION, AND CHARACTERIZATION}

\author{
Synthesis of Citrate Gold Nanoparticles (CGN): CGN were synthesized using the gold citrate
} method in which gold chloroauric acid is reduced by trisodium citrate [109]. In this process, 2.2-2.4 mL 1\% $\mathrm{wt} / \mathrm{v}$ citrate (Fischer Scientific) and $200 \mathrm{~mL} 0.01 \% \mathrm{wt} / \mathrm{v} \mathrm{HAuCl}_{4}$ (Alfa Aesar, MA) are mixed and heated to boiling, which promotes the reaction of sodium citrate to citric acid. Once the reaction is complete and allowed to cool, the solution is concentrated using a rotovapor (Buchi Rotovapor System) to $\sim 20 \mathrm{~mL}$ before the addition of any layering.

Synthesis of Silica Gold Nanoshells (SGN): SGN have an inner core composed of silica with an outer coating of gold $[75,110]$. Synthesis of these particles follows the Stober method [111-114] consisting of four main stages: production of small gold seed particles, fabrication of monodispersed silica cores, attachment of gold to the seed particles, and gold shell growth. The gold colloid solution is created using the recipe from Duff, Langmuir 1993 [115]. Growth of the silica cores requires the combination of $7.5 \mathrm{~mL}$ tetraethyl-orthosilicate (Sigma Aldrich, 333859), $225 \mathrm{~mL}$ absolute ethanol (Decon Labs), and 12.5-13.5 mL ammonia (Sigma Aldrich) [56]. The amount of ammonia is adjusted to achieve silica core sizes $110+/-5$ $\mathrm{nm}$. After the paraffin cover is removed and the ammonia is evaporated, the cores are modified by coating with 3-4\% aminopropyltriethoxysilane (APTES) (Sigma Aldrich, 440140). Once the seeds are washed, the $10 \%$ gold solution (THPC) is added. After reaction time, the seeds are washed and the pellet is redispered in DI water. The optical density is measured (Varian Cary 50Bio UV-Visible Spectrometer) and the seeds are diluted to a lowOD (optical density) at $530 \mathrm{~nm}$. Next, a sweep of the seeds is performed to optomize the chemical ratio between seeds, $\mathrm{K}_{2} \mathrm{CO}_{3}-\mathrm{HAuCl}_{4}$, and formaldehyde (Fischer Scientific F79). Once an optimal ratio is found, the reaction can be scaled up with appropriate amounts of THPC with seeds, Potassium Carbonate, and Formaldehyde [56]. 
Particle Functionalization: The first layer applied to the CGN was hexadecathiol (Sigma Aldrich 471364) dissolved in ethanol [52]. While stirring, $20 \mathrm{~mL}$ pure ethanol (Decon Labs) was placed in a breaker with $60 \mathrm{uL}$ 1-Hexadecathiol being added secondly. The nanoparticles were added to the sample slowly dropwise. After agitating sample for 20 minutes, it was placed on an orbital rocker (Orbitron Rotator, Boekel Scientific) for 12 hours. The sample was spun down and the pellet washed twice and resuspended in chloroform (Sigma Aldrich, 288360). The second was the addition of the PC (Avanti Lipids), a type of phospholipid that is a major component of biological membranes [73]. The PC (10 $\mathrm{mg} / \mathrm{mL}$ chloroform) stock solution was added to the particles after the -thiol layer and was allowed to set overnight on the orbital rocker. The solutions are transferred to glass tubes and the chloroform is evaporated at ambient temperature. This completed the two layer nanoparticles, and will be referred to as $\mathrm{C}_{\mathrm{AU}} / \mathrm{TL} / \mathrm{PC}$ (citrate gold/thiol/phosphatidylcholine) and NS/TL/PC (nanoshell/thiol/phosphatidylcholine).

The next type of particle was synthesized after the addition of the PC. HDL from human plasma (Sigma Aldrich L1567) was added to the particles to promote active targeting since HDL is highly expressed in various forms of cancer, as well as hepatocellular tissue [74, 116, 117]. After the addition of HDL, the nanoparticles were allowed to react overnight. The addition of the HDL layer yielded the three layer nanoparticle, referred to as $\mathrm{C}_{\mathrm{AU}} / \mathrm{TL} / \mathrm{PC} / \mathrm{LP}$ and NS/TL/PC/LP.

PEGylation of nanoparticles is considered the most common form of surface modification for delivering nanoparicles into cancdcerous tissue. In this study, PEGylated nanoparticles are used as the control to compare the efficacy of the newly synthesized two- and three layer nanoparticles. Numerous studies have shown that pegylated particles remain in the circulation longer than non-PEGylated nanoparticles [57]. For this study, the two types of layered particles, $\mathrm{C}_{\mathrm{AU}} / \mathrm{TL} / \mathrm{PC}$ or NS/TL/PC and $\mathrm{C}_{\mathrm{AU}} / \mathrm{TL} / \mathrm{PC} / \mathrm{LP}$ or NS/TL/PC/LP, are compared to the $\mathrm{C}_{\mathrm{AU}} / \mathrm{PEG}$ (citrate gold/pegylated) particles and NS/PEG. To create the pegylated particles, both the citrate gold nanoparticles and silica gold nanoshells are incubated with 2000 MW poly(ethylene)glycol overnight.

Particle Characterization: Four methods were employed to ensure correct functionalization of the nanoparticles. (i) Particles were analyzed using the Varian Cory 50 Bio UV-Visible Spectrometer to obtain maximum absorption wavelengths. (ii) Size and zeta potential measurements were obtained using the ZetaSizer Nanoseries ZS90 from Malvera Instruments. (iii) Morphology and size of the nanoparticles were 
determined using a Zeiss Supra 35VP scanning electron microscope (SEM). (iv) Presence of lipids on the surface of the particles was confirmed using the Fourier transform infrared (FTIR) (Perkin Elmer Spectrum BX) and through visual analysis using the SEM. 


\section{CELL CULTURE WORK}

Cell Cultures: The human lung adenocarcinoma cell line A-549 and the liver hepatocellular carcinoma cell line HepG2 were maintained in Dulbecco's modified Eagle's medium (Sigma R0883) with $10 \%$ fetal bovine serum (Atlanta Biologicals, GA) and 1\% penicillin-streptomycin-glutamine solution (HyClone 100X, Thermo Scientific) in a humidified atmosphere of $5 \% \mathrm{CO}_{2}$ at $37^{\circ} \mathrm{C}$ (NAPCO Series 8000 DH, Thermo Scientific). The S2VP10 (pancreatic cancer) cell line was grown in RPMI 1640 (Cellgro 10040-CV) with $10 \%$ fetal bovine serum (Atlanta Biologicals, GA) and 1\% penicillin-streptomycin-glutamine solution (HyClone 100X, Thermo Scientific) in a humidified atmosphere of $5 \% \mathrm{CO}_{2}$ at $37^{\circ} \mathrm{C}(\mathrm{NAPCO}$ Series 8000 DH, Thermo Scientific). Cells were grown in T-75 flasks (Corning, NY) to 80\% confluency before plated in 3D cell culture formation. Using 24 well round bottom ultra-low attachment plates (Corning, NY), 100,000 cells were placed in each well and lightly shaken for $\sim 15 \mathrm{~min}$. Spheroid formation occurred after 7-14 days by self-aggregation.

Nanoparticle Treatment: After optimal 3D cell culture growth was established, $40 \mu \mathrm{L}$ of $25.0 \mathrm{OD}$ (optical density) of each particle type was added to each well. All experiments were done in triplicate. The 3D cell cultures were incubated for six hours. The remaining media along with any remaining nanoparticles were removed from the wells. Each well was washed with $1 \mathrm{~mL}$ PBS, and each tumor was transferred to a microcentrifuge tube.

Cryosectioning of in vitro tumors: Cryosectioning was performed using a Leica CM1860 Cryostat. For this procedure, tumor spheroids were placed in cryomolds made from Tissue Freezing Medium (Triangle Biomedical Sciences). Once the samples were allowed to dry in the tissue freezing medium for two hours, they were sectioned at $5 \mu \mathrm{M}$. Settings for the cryostat included a chamber temperature of $-20^{\circ} \mathrm{C}$, block temperature of $-50^{\circ} \mathrm{C}$, and sample temperature of $-25^{\circ} \mathrm{C}$. As the samples were sectioned, each section was applied to a Superfrost ${ }^{\circ}$ Plus Microscope Slide (Fischer Scientific, 1255015). Tumor existence was confirmed on each slide using an inverted light microscope. 


\section{NANOPARTICLE DETECTION IN 3D CELL CULTURES}

Detection of Nanoparticles in 3D Cell Culture using Silver Enhancement Stain: After sectioning of spheroids, slides were first placed in cold acetone (Fischer Scientific) for $30 \mathrm{sec}$. Slides were removed from acetone and allowed to dry for one minute. Next, slides were placed in 10\% formalin buffer (Sigma Aldrich) for three minutes. Slides were removed and washed using DI water two times. While slides were air dried for five minutes, the silver enhancement solution was prepared by mixing $1 \mathrm{~mL} /$ slide Silver Enhancement Stain A (Sigma Aldrich, S5070) along with $1 \mathrm{~mL} /$ slide Silver Enhancement Stain B (Sigma Aldrich S5145). The two solutions were mixed in a $50 \mathrm{~mL}$ tube and vortexed for 2 minutes. Next, $2 \mathrm{~mL}$ of the combined solution was added to each slide and allowed to react for six minutes. The solution was washed off using DI water two times after reacting. Slides were analyzed using an NIS Elements AR and an Accuscope 3032 inverted light microscope. Using the program, ROI intensity measurements were recorded for both the stained and unstained samples.

Detection of Nanoparticles in 3D Cell Culture using Hyperspectral Imaging: To determine nanoparticle diffusion within the 3D cell cultures, the CytoViva Hyperspectral Imaging System was used (generously provided by the Department of Bioengineering at the University of Louisville). An Olympus BX43, fitted with a condenser from Cytoviva, was utilized for the dark-field microscopy. Images were captured at 60x magnification using the Dage XLMTC optical camera. Samples were prepared by soaking in cold acetone, $10 \%$ neutral buffer formalin, and dipping in $\mathrm{dH}_{2} \mathrm{O}$. Once the slides were dried, the region around the tissue was identified by bright-field microscopy and marked for ease of identification. A drop of oil was placed on the slide and a coverslip attached. Then, a drop of oil was placed on the condenser, and the condenser was brought into contact with the slide. The light source was focused and aligned at 10x magnification in order to produce the best quality images. Another drop of oil was placed on top of the coverslip, and an oil-immersion 60x magnification objective was then focused.

Images were captured at 12-bit resolution at a size of 2048x2048 pixels using Dage Xponent7. At 60X magnification, a distance of $1 \mu \mathrm{m}$ measured to 8.1 pixels. However, given the light-scattering properties of the nanoparticles, they appeared larger than their actual size and were easily identified. Image 
analysis was performed using NIH ImageJ. An automatic filtering algorithm was applied to all images, which separated out the majority of the particles from the background of tissue. [118] To ensure that no particles were inadvertently filtered, measurements were taken utilizing both the original and the filtered image simultaneously. Images of nanoparticles alone were used to determine the average appearance of size of the nanoparticles. A known area of the image was measured, and the ROI intensity was recorded. The number of particles was then manually counted, and the ROI intensity was divided by the particle count in order to determine the average size particle.

The number of particles present within a given area was then manually counted, using this average particle size for reference in order to form a reasonable estimate in the case of aggregated particles within the tissue. Many different regions were analyzed on each image in order to visualize the diffusion gradient of the nanoparticles into the center of the cancer tissues. The results were then compared internally to determine if a particular particle composition and surface modification penetrated the tissue more easily.

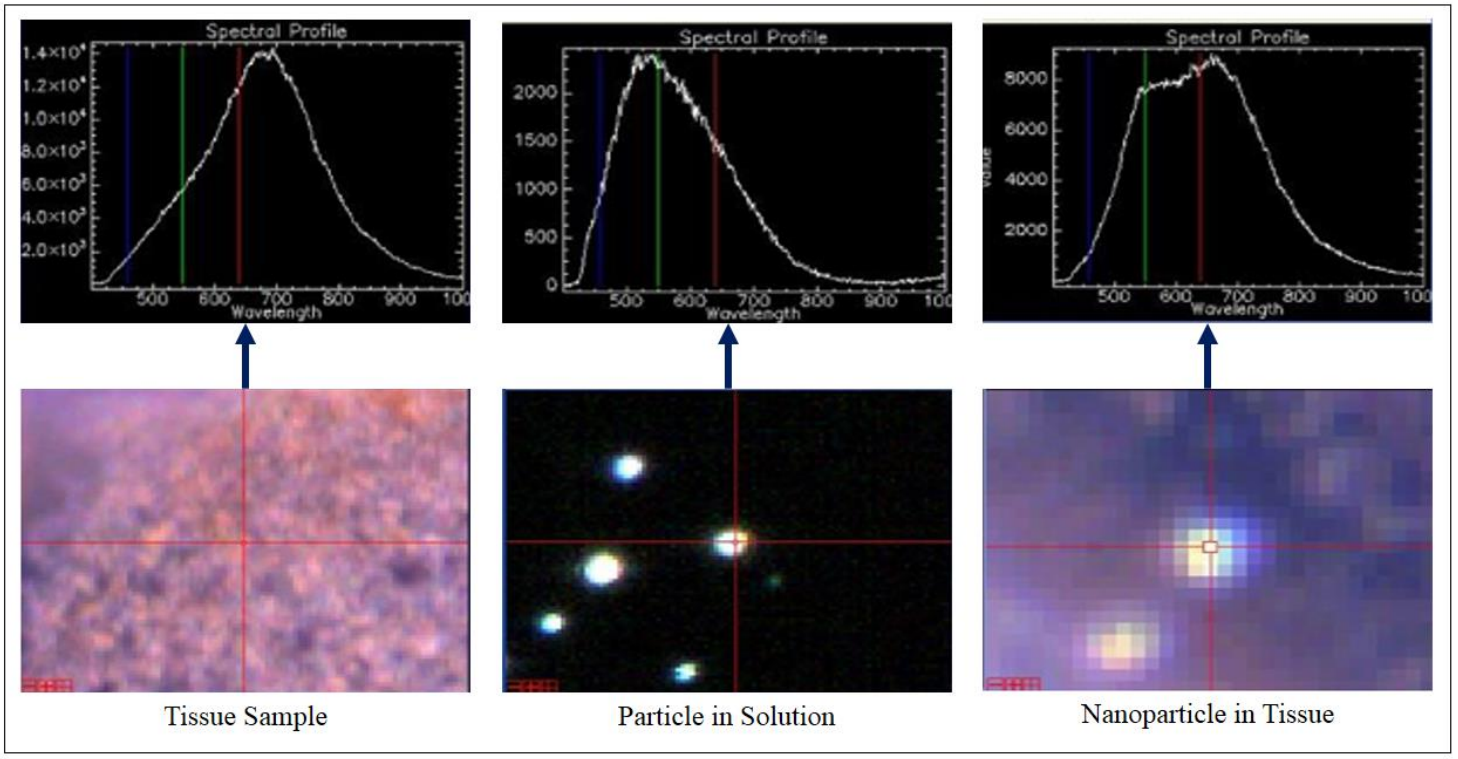

Figure 3: CytoViva Hyperspectral Imaging. The CytoViva Hyperspectral Imaging system was used to confirm the presence of nanoparticles. As shown above, specific spectral profiles were established for the nanoparticles alone, tissue alone, and particles within the tissue. Once spectral profiles had been created, the software could determine the particle locations within the tissue. 
Quantification of CytoViva Hyperspectral Imaging Data: Data obtained from the CytoViva Hyperspectral Imaging analysis was used to calculate the number of particles present in the outer $50 \mu \mathrm{m}$ layer of the spheroid. Diffusion equations were fitted to the data and the total number of particles was calculated by integrating the product of the spherical and diffusion equations. For more information, please see Results.

Statistical Analysis: All statistical analyses used the two-tailed Student's $t$ test with significant values being less than 0.05 . We used this test because each portion of the study presented one nominal and one measureable variable, thus enabling a comparison between the mean values of the measured variables. This analysis was sufficient to determine statistical significance within the $95 \%$ range. Statistically significant results are illustrated with an $(*)$ in the Results. 


\section{RESULTS}

\section{NANOPARTICLE FUNCTIONALIZATION AND CHARACTERIZATION}

Nanoparticle Characterization: CGN and SGN were layered with either two- or three layers (Figure 4) to promote enhanced penetration into 3D cell cultures as a representative model of hypoxic regions of solid tumors, and their performance was compared to PEGylated particles. To ensure identity, nanoparticles were characterized using UV-Visible spectroscopy, zeta potential analysis, scanning electron microscopy, and FTIR. The CGN spectrum was found to have a maximum absorption at $530 \mathrm{~nm}$ (Figure 5A), which is indicative of citrate gold nanoparticles. The SGN spectrum revealed wavelengths in the near infrared region around $820 \mathrm{~nm}$ (Figure 5B), which is common for nanoshells having $110 \mathrm{~nm}$ diameter silica cores, along with $\sim 10 \mathrm{~nm}$ gold coating [119].

Zeta potential of nanoparticles refers to the surface charge in solution. Data from previous studies provide estimates of expected zeta potential values based upon surface modifications, yet zeta potential is dependent on many other factors including size and conformation. In agreement with previous results, PEGylated nanoparticles possessed a zeta potential ranging between -7 to $-20 \mathrm{mV}[44,120]$, the addition of -thiol and PC caused an increase in negativity from $-20 \mathrm{mV}$ to $-30 \mathrm{mV}$ [121], and the addition of HDL produced particles with a slightly negative potential [122]. For CGN, the PEGylated control exhibited a zeta potential of $-9 \mathrm{mV}$, the two layer particles had $-20 \mathrm{mV}$, and the three layer particle had $-2 \mathrm{mV}$ (Figure 5C). The PEGylated SGN exhibited a zeta potential of $-18 \mathrm{mV}$, the tw o layer nanoshell was $-29 \mathrm{mV}$, and the three layer nanoshell was $-7 \mathrm{mV}$ (Figure 5). 


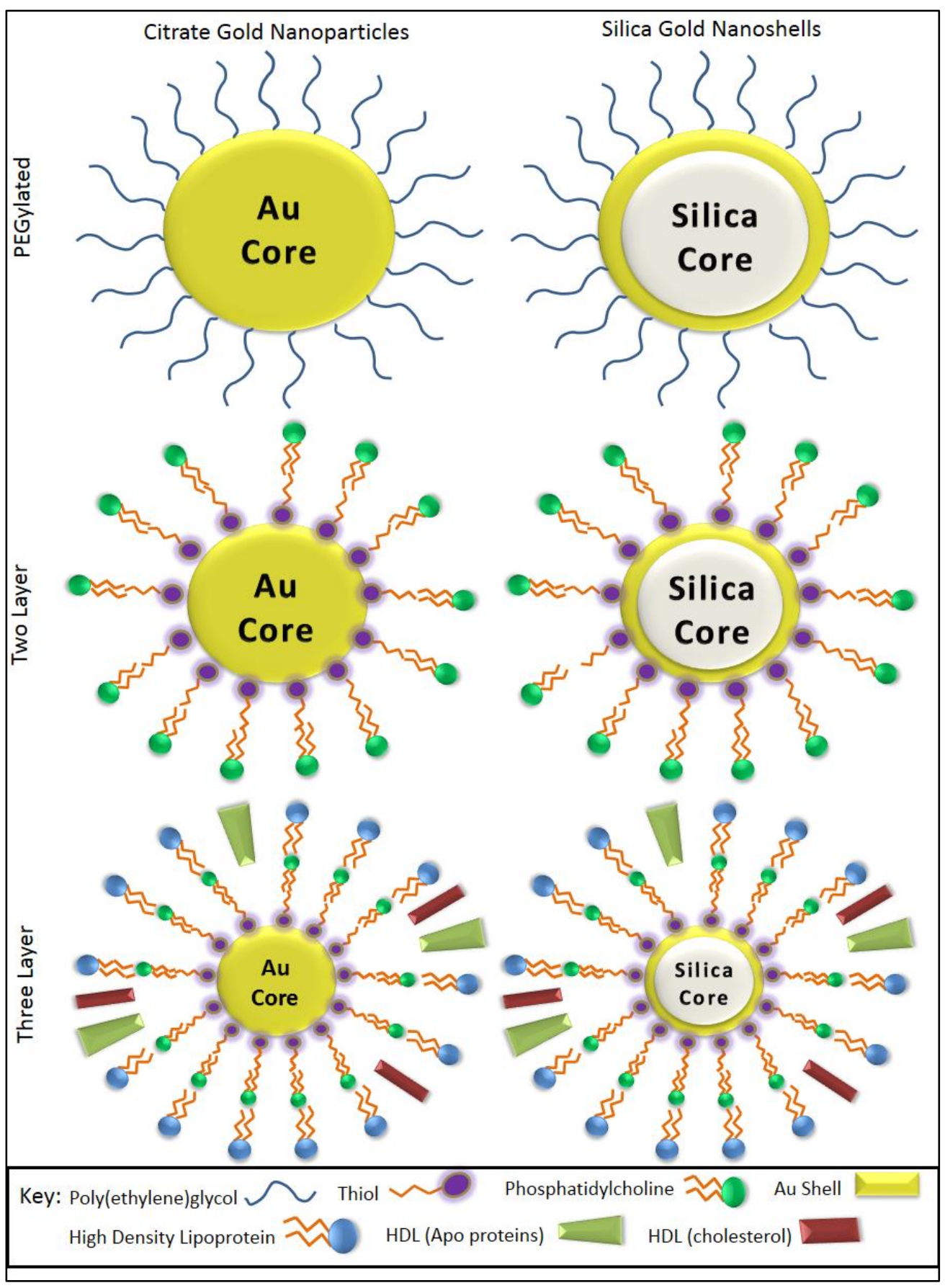

Figure 4: Illustration of Functionalized Silica Gold Nanoshells and Citrate Gold Nanoparticles. Six types of particles are shown including CGN and SGN. Nanoparticles were functionalized to form PEGylated nanoparticles, two layer nanoparticles (-thiol and PC), and three layer nanoparticles (-thiol, PC, and HDL). 


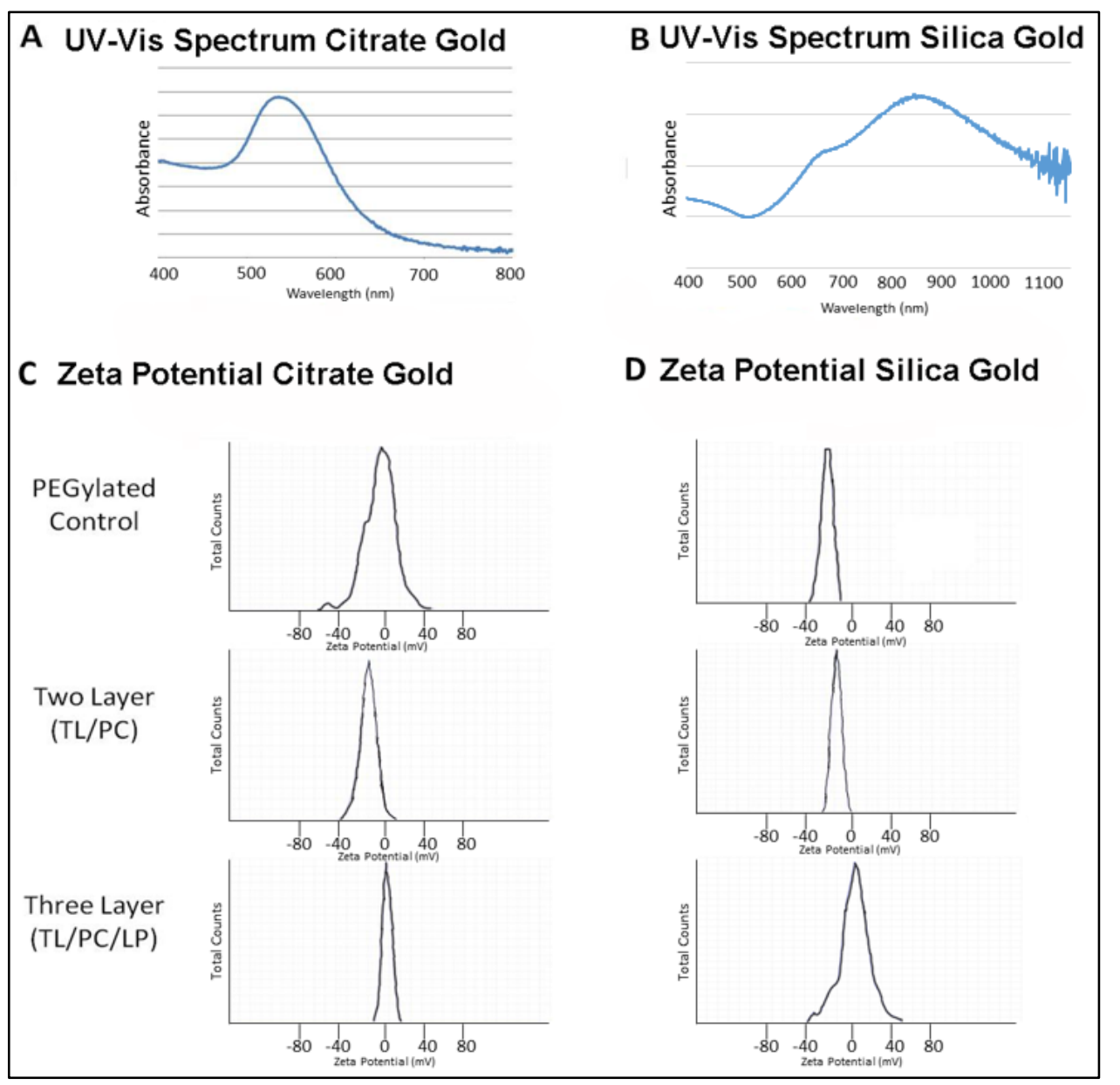

Figure 5. Characterization of SGN and CGN by UV-Visible Spectroscopy and Zeta Potential Analysis. (A) Spectra of CGN indicate a maximum absorption at $\sim 535 \mathrm{~nm}$. (B) Spectra of SGN suggests a maximum absorption at $\sim 820 \mathrm{~nm}$. For verification of surface modifications, zeta potential analysis is shown below the spectra as an indication of surface charge. (C) PEGylated CGN had a zeta potential of $-9 \mathrm{mV}$, the two layer CGN had $-20 \mathrm{mV}$, and the three layer CGN had $-2 \mathrm{mV}$. (D) A zeta potential of $-18 \mathrm{mV}$ was found for the PEGylated SGN, $-29 \mathrm{mV}$ for the two layer SGN, and $-6.8 \mathrm{mV}$ for the three layer SGN. 
To ensure the presence of surface modifications, fourier transform infrared (FTIR) spectroscopy was employed (Figure 6). Spectra obtained were observed and compared to literature sources. For HDL, there is an $-\mathrm{OH}$ stretch and $-\mathrm{CH}_{3}$ stretch in the $2800-3400$ wavenumber $/ \mathrm{cm}^{-1}$ region with other characteristics found in the $1500-1800$ wavenumber $/ \mathrm{cm}^{-1}$ region [123]. For PEGylated nanoparticles, there were slight differences in the $1500-1000$ wavenumber $/ \mathrm{cm}^{-1}$ range with three bands assignable to the $-\mathrm{CH}_{2}$ and $-\mathrm{CH}_{3}$ groups [124]. The FT-IR spectra of PC coated two layer nanoparticles show alterations in the region from 1065-1100 and $\sim 1250$ wavenumber $/ \mathrm{cm}^{-1}[125]$.

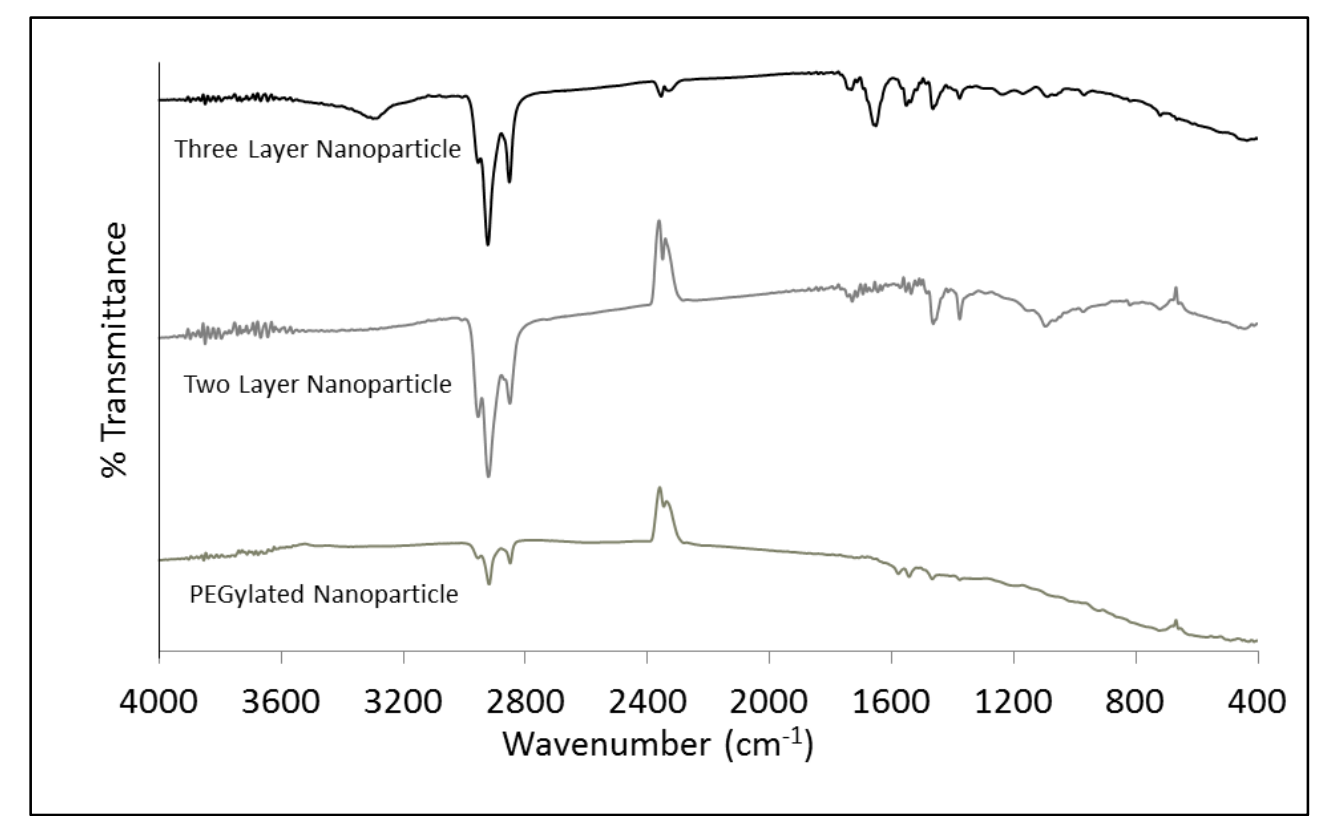

Figure 6. Determination of Surface Functionalizing using FTIR. (Top) Three layer nanoparticles containing -thiol, PC, and HDL. (Middle) Two layer nanoparticles containing -TL and PC. (Bottom) PEGylated nanoparticles. Regions between 1400-1600 wavenumber $/ \mathrm{cm}^{-1}, 2800-3100$ wavenumber $/ \mathrm{cm}^{-1}$, and others were analyzed to differentiate between lipids and poly(ethylene)glycol.

Scanning electron microscopy was used to further ensure the identity of the nanoparticles (Figure 7). Nanoshells had a circular morphology of $\sim 150 \mathrm{~nm}$ diameters. Presence of surface modifications was detected in the images by the halos surrounding the nanoparticles. The SGN are monodispersed and are less 
likely to form aggregated. Images of CGN indicated a polydispersed variety of particles including more circular and rod-shaped particles. The size of the particles varied from 40 to $75 \mathrm{~nm}$ and indicates some degree of aggregation. The halo affect can also be seen around the citrate gold nanoparticles indicating the presence of surface modifications.
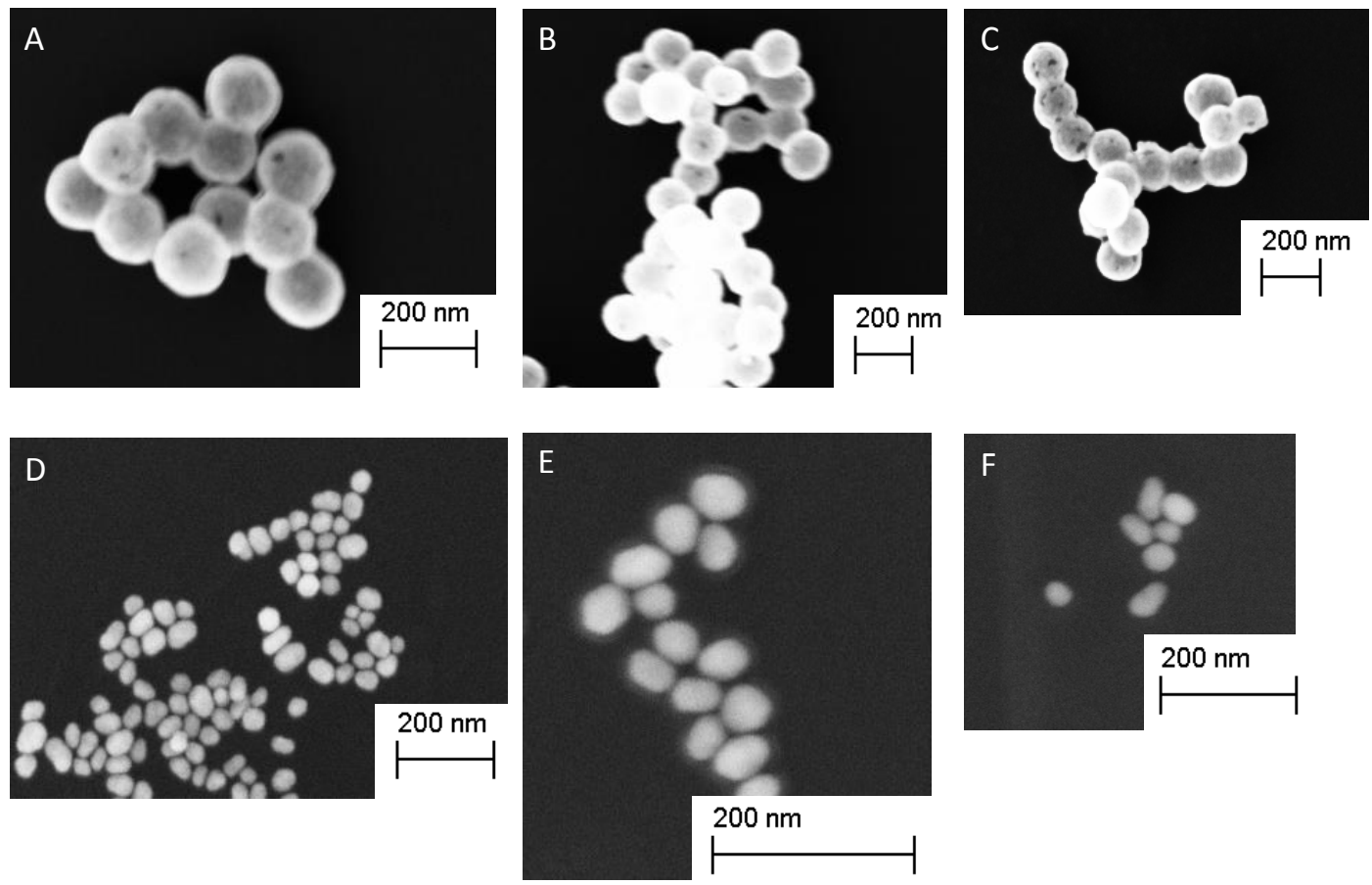

Figure 7. Scanning Electron Images of Functionalized Silica Gold Nanoshells and and Citrate Gold Nanoparticles. PEGylated silica gold nanoshells (A) indicate particle size to be around $150 \mathrm{~nm}$ in diameter. Surface modifications of two layer (B) and three layer (C) silica gold nanoshells can be seen by the halo effect around the particles. Citrate gold nanoparticles were much smaller than the nanoshells having an average diameter of $\sim 50 \mathrm{~nm}$. These particles seemed to form clusters, as did the PEGylated citrate gold nanoparticles (D). The polydispersed two layer (E) and three layer (F) were approximately the same size. 


\section{NANOPARTICLE ACCUMULATION IN 3D CELL CULTURES}

Analysis of Nanoparticle Uptake by Silver Enhancement Staining: Use of silver enhancement staining for detection of nanoparticles is common practice [126], yet does not provide sufficient quantification about the number of particles present in samples (Figure 8). Staining was evaluated using an inverted bright field microscope with imaging analysis tools [127]. The results in ROI intensity were measured and compared to unstained and stained samples. Differences between unstained samples and stained samples were extracted in order to obtain approximate nanoparticle accumulation in the 3D cell cultures.

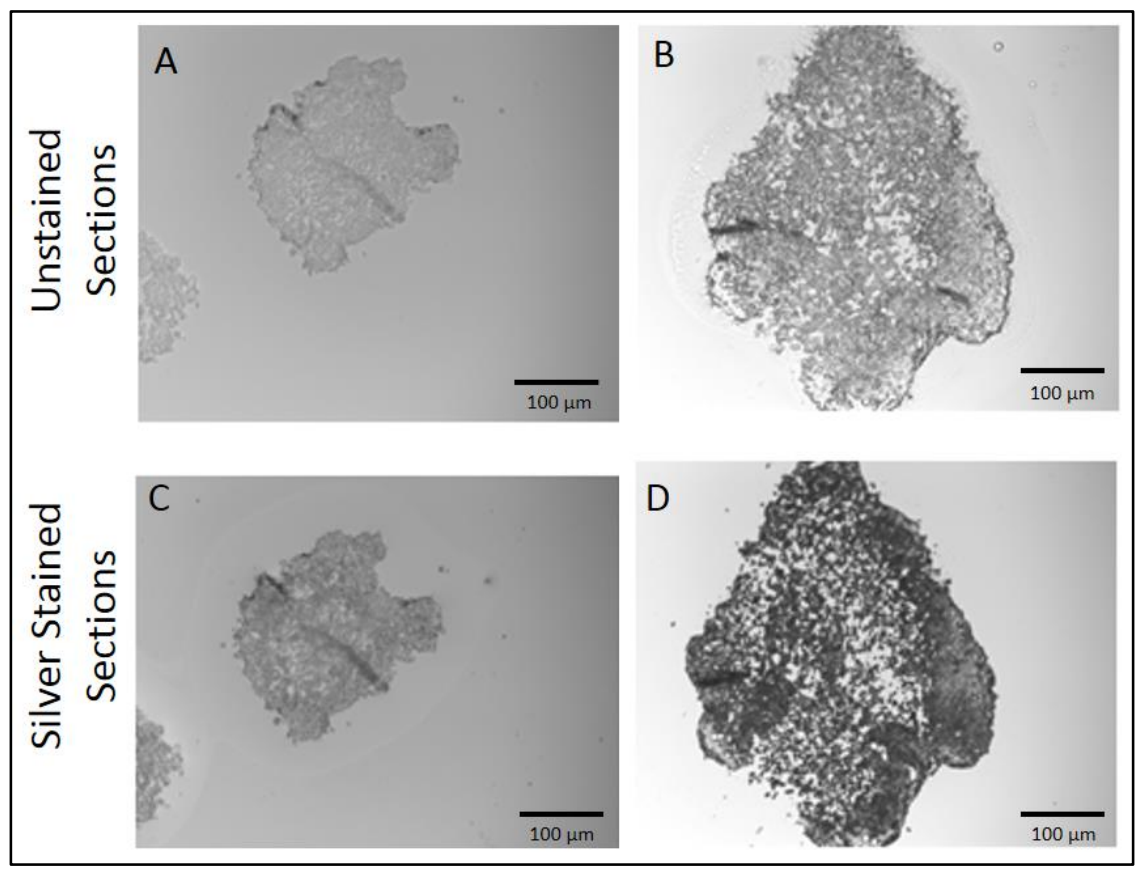

Figure 8: Detecting Nanoparticle Presence in 3D Cell Cultures through Silver Staining. ROI intensities were measured for both unstained sections of tissue and silver stained sections; darker regions denote an increase in ROI intensity. 20X image of A549 3D cell culture (A) before and (B) after silver staining. 20X image of HepG2 3D cell culture (C) before and (D) after silver staining. 
Nanoparticle Diffusion through 3D Cell Cultures: In order to determine particle diffusion within tumor tissue, ROI measurements were taken at the periphery and center of the $3 \mathrm{D}$ cell cultures using the silver enhancement stain (Figure 9). In the HepG2 cell line, the largest difference between periphery and center regions was exhibited by the two layer CGN (Figure 9A). Two layer SGN presented similar ROI intensity values for both the periphery and interior of the 3D cell cultures, suggesting that particles were able to diffuse more uniformly into the tissue. Further, these values were the highest of all the cases. Three layer CGN also exhibited similar intensities between the periphery and interior of the 3D cell culture, yet at lower values indicating poorer penetration. The PEGylated particles revealed noticeable differences between the periphery and the center region while showing the lowest overall uptake.

In general, the A549 cell line displayed decreased uptake in comparison to the HepG2 3D cell cultures (Figure 9B). Three layer SGN had a more uniform particle distribution while the two layer had higher penetration but with an increased differential between the periphery and the interior. Three layer CGN exhibited higher ROI and more uniform values as compared to the other CGN. On the other hand, the S2VP10 cell line exhibited ROI intensity values highlighting the difficulty for particles to penetrate deeper into the 3D cell cultures (Figure 9C), with the peripheries generally having higher ROI values compared to the center regions. The three layer nanoshell had higher uptake in the periphery and center regions as compared to the two-layer and PEGylated SGN. Both the two- and three layer CGN presented similar ROI intensity values. 


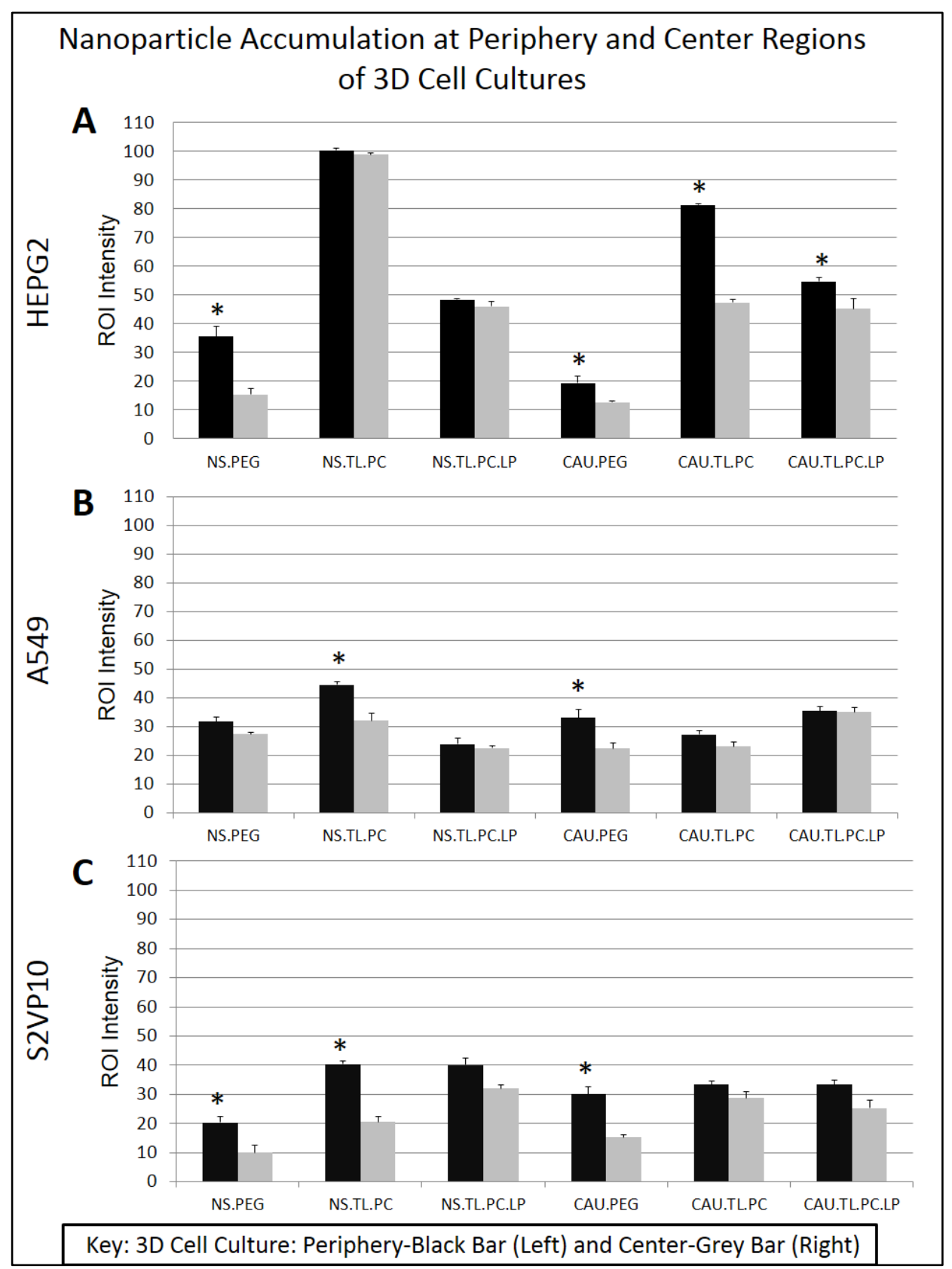

Figure 9. ROI Intensity Comparison between 3D Cell Culture Periphery and Inner Regions. ROI intensity measurements were taken around the periphery (black bar) and in center regions (grey bar) of the 3D cell cultures. Incubation of nanoparticles with two- and three layer CGN and SGN exhibited increased amounts of particles on the periphery with a decreased amount towards the center of the tumors. (A) For the HepG2 3D cell cultures, there are significant differences in the SGN uptake, with the two SGN having an ROI intensity of $\sim 100$ for both the periphery and center of the 3D cell culture. There are only subtle differences for the CGN. (B) For the A549 3D cell cultures, the ROI difference between the edge and center is smaller, 
while the ROI intensities are less than those seen in panel A. The two layer SGN and three layer CGN exhibited higher ROI intensities within the center portions of the 3D cell culture. (C) For the S2VP10 3D cell cultures, the three layer SGN presented higher accumulation in the center regions of the 3D cell culture, while both the two- and three layer CGN exhibited similar ROI intensity measurements.

To further examine nanoparticle diffusion, 3D cell cultures were examined with dark field microscopy (Figure 10). In all cases, the two and three layer particles penetrated deeper and more uniformly than the PEGylated particles (Figure 11). For the HepG2 cell line, the most uniform penetration occurred with the three layer CGN and the two layer SGN (Figure 11A-B). For the A549 cell line, the three layer CGN outperformed the other CGN, while all the SGN showed similar penetration capabilities (Figures 11C-D). For the S2VP10 cell line, all the cases showed non-uniform penetration, with the three layer CGN and SGN having a slight advantage over the other types.
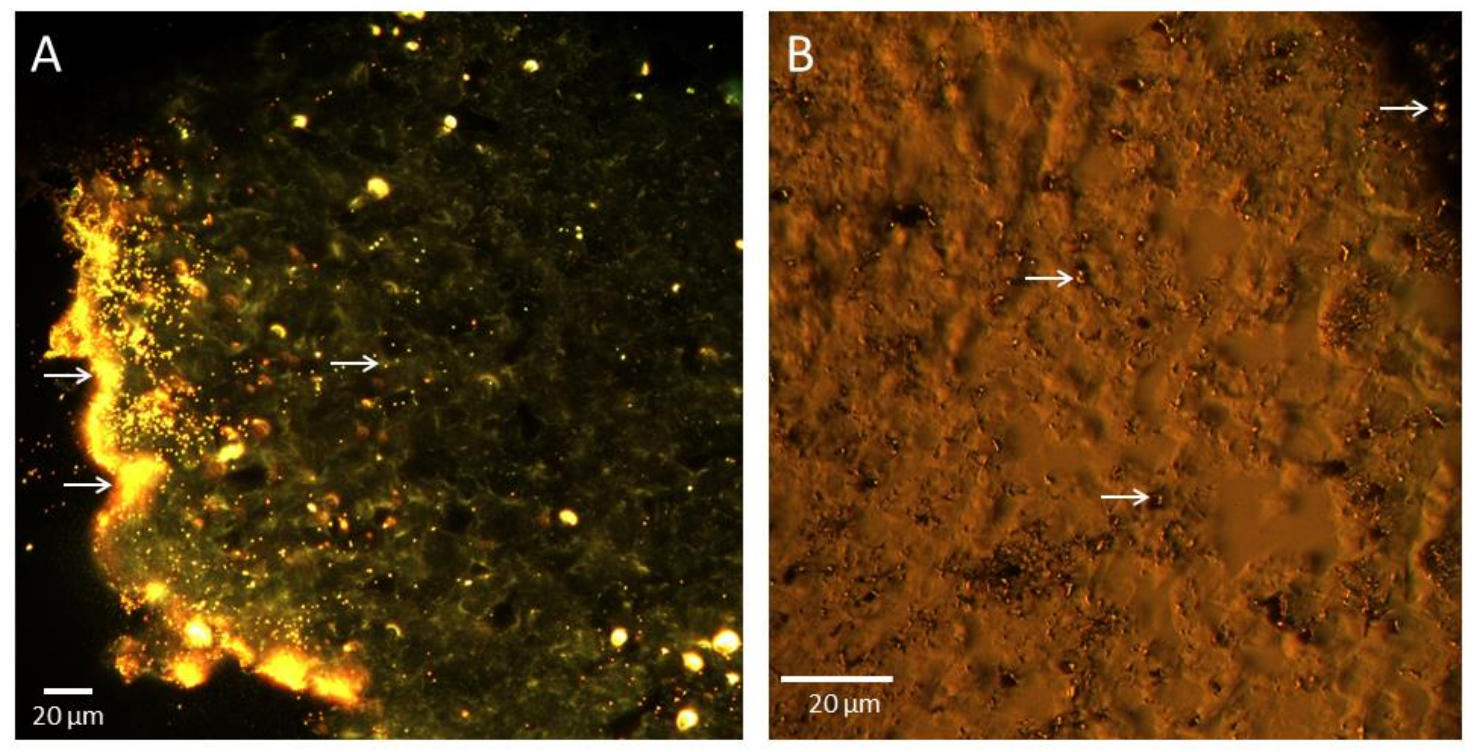

Figure 10: Detection of Nanoparticles within 3D Cell Cultures Using Dark Field Microscopy. Nanoparticle uptake was determined using the CytoViva setup with a dark field microscope to visualize the nanoparticles and hyperspectral imaging to confirm particle identity. (A) 60X image of 3D cell culture showing increased particle concentration around HepG2 3D cell culture periphery with decreasing particle numbers towards the inner region. (B) 100X image of A549 3D cell culture illustrating the presence of particles distributed throughout the tissue. Arrows indicate individual particles. 


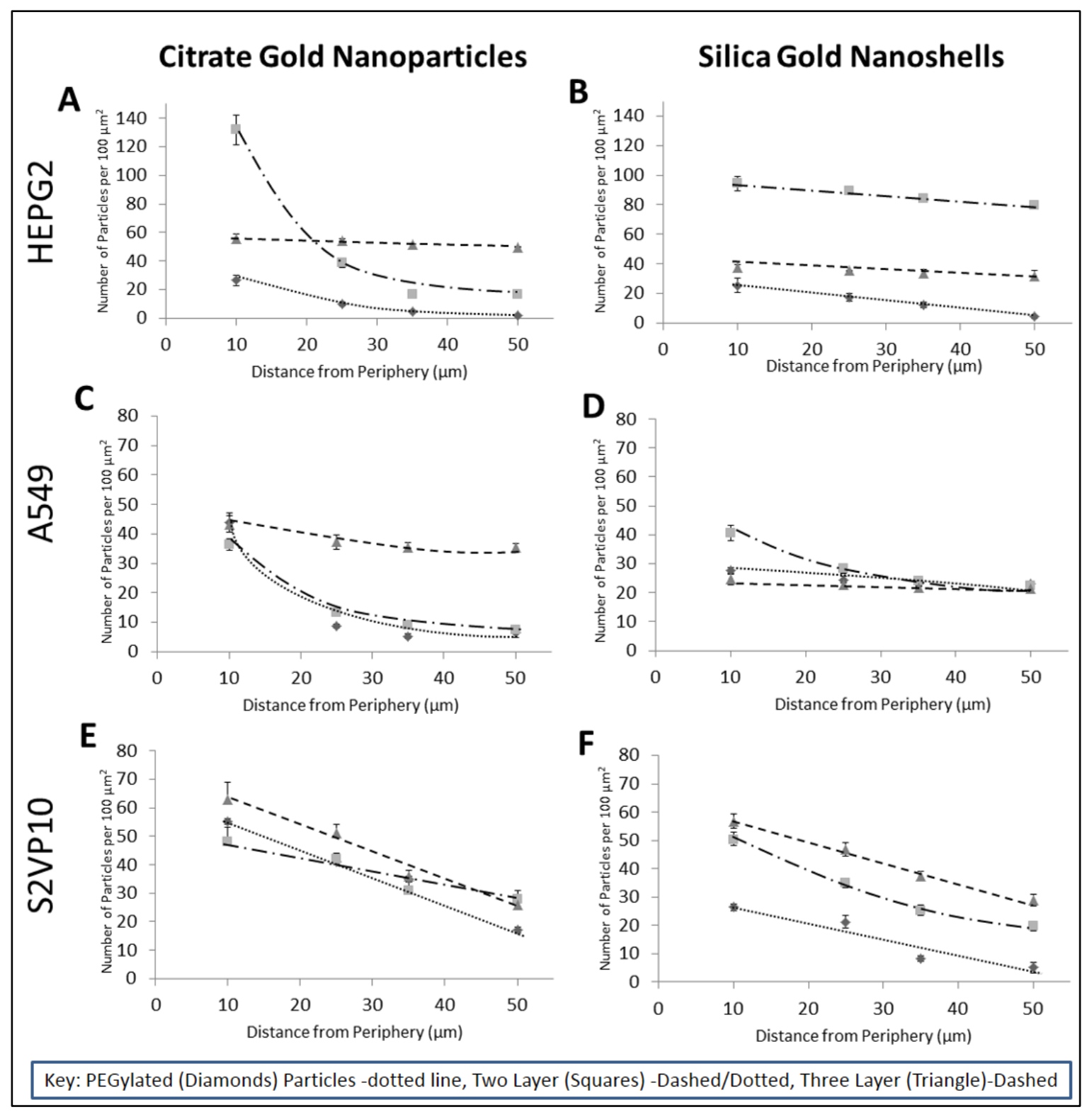

Figure 11. Nanoparticle Diffusion into Inner Regions of 3D Cell Cultures. Diffusion of nanoparticles from the periphery of 3D cell cultures into inner regions was confirmed using dark field microscopy. On the left, CGN are shown while the right column represents SGN. (A) Two layer CGN had the highest particle concentration around the periphery with a steep decline into the center regions, whereas the three layer particles exhibited a more uniform penetration with higher concentrations within the inner regions. (B) Two layer SGN presented a higher and more uniform diffusion from the periphery to the center regions of the HepG2 3D cell culture compared to the CGN. (C) The two layer CGN presented uniform penetration in the 
A549 3D cell cultures. (D) Two layer SGN showed elevated accumulation around the periphery of the A549 3D cell cultures, yet with no statistical difference between particle accumulation in the center regions. (E) Steep diffusion gradients are shown by (E) CGN and (F) SGN particles in the S2VP10 tumors 


\section{QUANTITATIVE ANALYSIS OF DIFFUSION GRADIENTS}

To further analyze diffusion data (Figure 11), diffusion equations were estimated for each particle in the three distinct cell lines. The equations were used to determine the number of particles that were able to penetrate and diffuse throughout the 3D cell cultures. Measurements were taken from the periphery to the spheroid inward to $50 \mu \mathrm{m}$. Diffusion data were fitted according to exhibit exponential traits that could be used for calculations. Exponential equations were used to calculate the number of particles present in the region of spheroid, which is from the periphery to $50 \mu \mathrm{m}$ toward the center as shown (Figure 12).

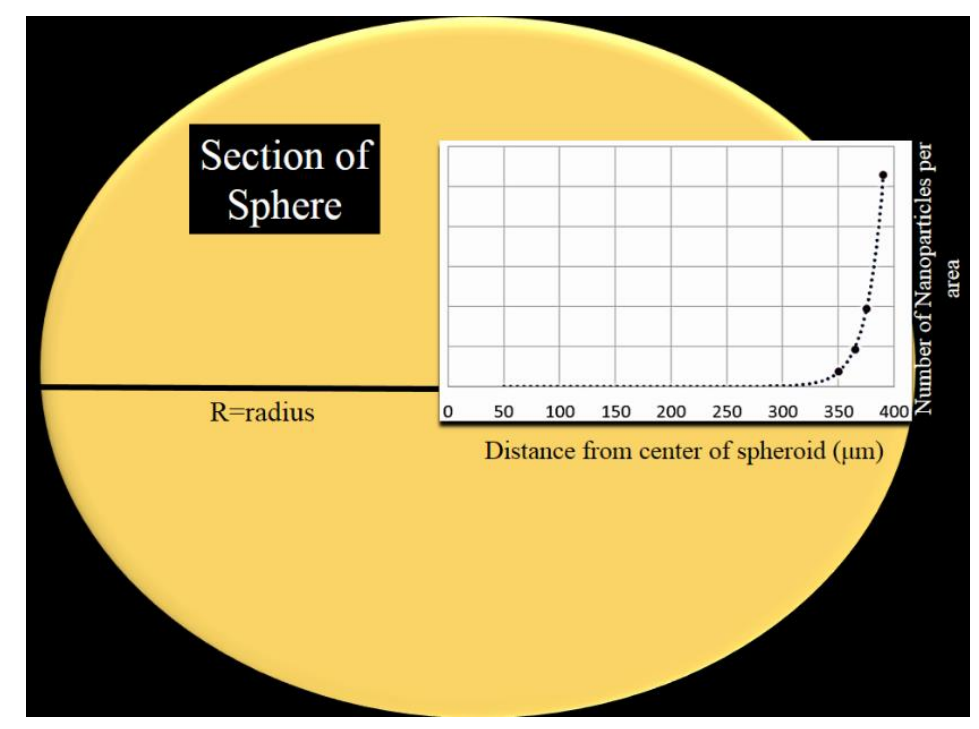

Figure 12: Illustration of Tumor Spheroid Nanoparticle Diffusion. The amount of nanoparticles reaching inner portions of the 3D cell culture is much less than those able to penetrate the outer portion of the spheroid. The graph depicts the number of nanoparticles decreasing from $400 \mu \mathrm{m}$ (at the edge) inward to $\sim 325 \mu \mathrm{m}$. 
Two assumptions were made for the calculated to be valid. It was first assumed that all 3D cell cultures were spherical in shape, which allowed for simplification of the calculations. It was also assumed that all 3D cell cultures were roughly the same size, with the radius being $\sim 400 \mu \mathrm{m}$. Using these assumptions, Equation (1) was used to calculate nanoparticle accumulation.

(Equation 1) N.P. $=\int_{a}^{b} 4 \pi r^{2}\left(c e^{f r}\right) \mathrm{dr}$ where N.P. is the number of nanoparticles, a is $350 \mu \mathrm{m}, \mathrm{b}$ is $400 \mu \mathrm{m}, \mathrm{r}$ is the radius, $\mathrm{c}$ and $\mathrm{f}$ are constants. Diffusion equations (Table 1) were replaced into Equation 1 to ascertain the values found in Table 2. These values indicate the total number of nanoparticles within the outer $50 \mu \mathrm{m}$ area around the tumor spheroid (3D cell culture). 
Table 1: Specific Nanoparticle Diffusion Equations. Using the results from Figure 11, equations were determined for the nanoparticles in each cell line.

\begin{tabular}{|c|c|c|c|c|c|c|}
\hline & \multicolumn{2}{|c|}{ HEPG2 } & \multicolumn{2}{c|}{ A549 } & \multicolumn{2}{c|}{ S2VP10 } \\
\hline & CGN & SGN & CGN & SGN & CGN & SGN \\
\hline $\begin{array}{c}\text { PEGylated } \\
\text { (PEG) }\end{array}$ & $\left(2 \times 10^{-12}\right) e^{0.0633 x}$ & $\left(9 \times 10^{-9}\right) e^{0.0445 x}$ & $\left(3 \times 10^{-10}\right) e^{0.0533 x}$ & $\left(4.4 \times 10^{-2}\right) e^{0.0046 x}$ & $\left(1 \times 10^{-5}\right) e^{0.0276 x}$ & $\left(7 \times 10^{-7}\right) e^{0.033 x}$ \\
\hline $\begin{array}{c}\text { Two Layer } \\
\text { (TL/PC) }\end{array}$ & $\left(6 \times 10^{-11}\right) e^{0.0606 x}$ & $\left(1.8 \times 10^{-1}\right) e^{0.0043 x}$ & $\left(5 \times 10^{-8}\right) e^{0.0399 x}$ & $\left(1 \times 10^{-3}\right) e^{0.0151 x}$ & $\left(1.8 \times 10^{-3}\right) e^{0.0144 x}$ & $\left(4 \times 10^{-5}\right) e^{0.024 x}$ \\
\hline $\begin{array}{c}\text { Three Layer } \\
\text { (TL/PC/LP })\end{array}$ & $\left(7.4 \times 10^{-2}\right) e^{0.0606 x}$ & $\left(8.3 \times 10^{-2}\right) e^{0.0039 x}$ & $\left(3.9 \times 10^{-2}\right) e^{0.0061 x}$ & $\left(3.3 \times 10^{-2}\right) e^{0.00151 x}$ & $\left(9 \times 10^{-5}\right) e^{0.023 x}$ & $\left(8 \times 10^{-4}\right) e^{0.0168 x}$ \\
\hline
\end{tabular}




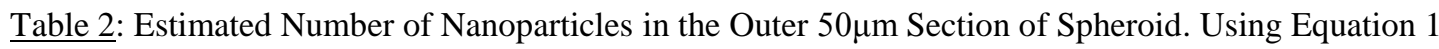
with the estimated diffusion equations, nanoparticle concentrations were calculated. This illustrates the estimated number of nanoparticles within the $50 \mu \mathrm{m}$. The highest number in each row has been outlined in red.

\begin{tabular}{|c|c|c|c|c|c|c|}
\hline & \multicolumn{2}{|c|}{ HEPG2 } & \multicolumn{2}{c|}{ A549 } & \multicolumn{2}{c|}{ S2VP10 } \\
\hline & CGN & SGN & CGN & SGN & CGN & SGN \\
\hline $\begin{array}{c}\text { PEGylated } \\
\text { (PEG) }\end{array}$ & $1.77 \times 10^{7}$ & $1.79 \times 10^{7}$ & $1.77 \times 10^{7}$ & $2.22 \times 10^{7}$ & $3.08 \times 10^{7}$ & $1.70 \times 10^{7}$ \\
\hline $\begin{array}{c}\text { Two Layer } \\
\text { (TL/PC) }\end{array}$ & $1.71 \times 10^{7}$ & $7.98 \times 10^{7}$ & $1.70 \times 10^{7}$ & $2.65 \times 10^{7}$ & $3.66 \times 10^{7}$ & $3.12 \times 10^{7}$ \\
\hline $\begin{array}{c}\text { Three Layer } \\
\text { (TL/PC/LP) }\end{array}$ & $3.42 \times 10^{7}$ & $3.17 \times 10^{7}$ & $3.42 \times 10^{7}$ & $5.19 \times 10^{6}$ & $4.80 \times 10^{7}$ & $4.04 \times 10^{7}$ \\
\hline
\end{tabular}

In each cell line, two- layer or three-layer nanoparticles showed optimal accumulation as compared to previously designed PEGylated nanoparticles. In HepG2 3D cell cultures, three-layer CGN and two-layer SGN exhibited enhanced accumulation compared to PEGylated nanoparticles (Figure 9 and 11). For the SGN, the increase in accumulation of two-layer nanoparticles compared to the PEGylated nanoparticles was approximately $78 \%$. The CGN depicted a 50\% higher accumulation of the three-layer nanoparticles compared to the PEGylated nanoparticles. For the A549 cell line (Figure 9 and 11), similar results were seen as in the HepG2 cell line. For CGN, three-layer nanoparticle was superior to the PEGylated nanoparticle by increasing accumulation by approximately $50 \%$. In the A549 cell line, two-layer nanoparticles provided the highest accumulation by approximately $15 \%$, which is much lower than the accumulation seen in the HepG2 cell line (78\%). Lastly, the S2VP10 cell line was unique in multiple ways (Figure 9 and 11). Both three-layer CGN and SGN presented optimal accumulation compared to the PEGylated nanoparticles in S2VP10 cell line. For CGN, there was a 35\% increase in comparison to PEGylated nanoparticles, while the increase of the SCG was approximately $42 \%$. 


\section{DISCUSSION}

Nanotherapeutics offer an enhanced targeting modality for transporting drug at higher

concentrations into solid tumors. The typically dysfunctional tumor vasculature, however, presents a physical obstacle for systemically-administered nanoparticles to reach hypoxic regions. In this study, we designed two and three layer citrate gold (CGN) and silica gold nanoshell (SGN) particles to enhance particle diffusion into tumor tissue, using 3D cell cultures to mimic the hypoxic (avascular) regions of solid tumors. From this study, we have shown that both PC (two layers) and PC-HDL (three layer) had increased accumulation in 3D cell cultures compared to previously synthesized PEGylated nanoparticles. This study also demonstrated a cancer-specific uptake of nanoparticles based upon functionalization entities. Lastly, this study exhibits the ability to numerically calculate the accumulation of nanoparticles within $3 \mathrm{D}$ cell cultures, making it an exceptional method for quantifying nanoparticle concentration in vivo. In clinical context, quantification can assist in developing specific treatment regimens based upon factors such as cancer type, functionalization of particles, and drug related properties.

The visible spectrum of nanoparticles can be altered by numerous factors including surface stabilization, size, shape conformation, and type of dispersion (mono- or poly-) [128-130]. From characterizing the particles, verification of the correct chemical synthesis can be ensured. The UV-Visible spectra of both the CGN and SGN (Figure 5) were within the expected value range with CGN $~ 535 \mathrm{~nm}$ and $\mathrm{SGN} \sim 820 \mathrm{~nm}$ (nanoshells were modified to the $820 \mathrm{~nm}$ wavelength for possible photothermal applications in the future [131, 132]).

Zeta potential (Figure 5) is modulated by surface functionalization and was shown to be $\sim 10 \mathrm{mV}$ for the PEGylated particles with two layer particles having increased surface negativity (-20 mV and -29 $\mathrm{mV}$ ) and three layer particles possessing more neutral charges. Zeta potentials can have a large impact on nanoparticle uptake since cellular membranes also possess negative charges $[133,134]$. In this study, we 
used particles with either neutral or slightly negative charges because particles with positive charges have been associated with cell wall disruption and particles with slightly negative charges will circulate throughout the body longer than positively charged particles [135]. One way to think about this is to remember that cell membranes have a slightly negative fixed charge [136], thus anything that is positive will almost instantaneously attract to the cell membranes. Longer circulating particles, those particles containing a slightly negative surface charge, will have fewer tendencies to adhere during the first round of circulation allowing the active targeting abilities of the nanoparticles to promote tumor uptake as compared to normal tissue uptake. Information obtained from the FTIR supported the correct synthesis and functionalization of the nanoparticles (Figure 6). Overall, the characterization process ensured the correct identity of the nanoparticles used in this study.

Data from the silver staining and specialized dark field microscopy was used to determine if lipid functionalized nanoparticles showed superior accumulation in comparison to PEGylated nanoparticles. In Figure 9, the enhanced accumulation of the two- and three-layered nanoparticles compared to the PEGylated nanoparticles is clearly visible, with the largest difference presented within the HepG2 cell line. The optimized uptake in the liver may be associated with the up-regulation of HDL. Further, the function of the liver is to filter materials as well as synthesize PC and HDL, thus the liver may have a higher probability of automatically interacting with any particle coated with PC or HDL. Previous studies have shown that nanoparticles tend to accumulate in the liver to be excreted through the bile $[137,138]$. This suggests that hepatocellular cancer and other cancers metastasized to this organ (e.g., colon), may be more susceptible to this type of nanoparticle.

While the hepatocellular 3D cell cultures produced the largest accumulation difference, the lung and pancreatic cancer cell lines also demonstrated increased uptake of the two- and three- layer particles, especially the nanoshells. This suggests that nanoshells may have enhanced penetration abilities due to properties of the nanoparticles such as the silica core size, amount of gold, or increased size. Overall, this evidence suggests that the SGN were able to penetrate the tumors as effectively as the CGN, but present a much more viable platform for targeted cancer therapy. Gold nanoshells have tunable optical properties, and photothermal treatment has shown to reduce cell viability significantly. [139, 140] 
This study also demonstrates the ability to numerically determine the amount of particles within a tissue sample, such as 3D cell cultures. Using 3D cell cultures or animal tissue, nanoparticle penetration and diffusion can be assessed for determining optimal particle type and funtionalization. From Figure 11, along with Table 1 and Table 2, nanoparticle accumulation at different locations within 3D cell cultures were shown suggesting an increased amount of nanoparticles around the periphery and decreasing particle quantities as you move toward the center of the spheroid. Diffusion rates from Figure 11 were used to determine the amount of nanoparticles estimated to be within the outer 50 micron region of the 3D cell culture. Table 2 clearly indicates that two- and three-layer nanoparticles were superior to PEGylated nanoparticles in each cancer line. There were some differences in accumulation of nanoparticles in the different cancerous tissue types. This difference in nanoparticle uptake could also be due to the physical morphology of the 3D cell cultures [141, 142]. While the HepG2 and A549 cell lines formed circular tumors, the highly metastatic S2VP10 cell line formed cell clusters, which could be a cause for differential particle uptake and diffusion. It is also well known that pancreatic tumors form a dense stroma that may hinder interstitial transport [143].

There are numerous studies showing size-dependent accumulation of nanoparticles within tissue samples. Previous studies suggest that CGN exhibit enhanced accumulation in tumors due to their smaller size ( 30\% that of SGN) [128]. Our study does this idea, with CGN accumulation of 135 particles/ $100 \mu \mathrm{m}^{2}$ for the periphery and SGN accumulation approximately 95 particles/ $100 \mu \mathrm{m}^{2}$. Although ROI intensities for both particles were similar, the surface area of one CGN is less than that of one SGN; to obtain similar ROI values requires more CGN per area than SGN (Figure 8 and 9). The smaller size of the CGN may therefore make their penetration less dependent on surface modifications, yet CGN are more likely to cause toxicity effects due to their solid gold nature (mostly through aggregation) as compared to the nanoshells [144].

This study represents an initial step to assess the performance of two- and three-layered lipid coated nanoparticles in penetrating solid tumor tissue. We find that diffusion gradients of nanoparticles can be detected in 3D cell cultures representing hypoxic tumor regions that are poorly vascularized. While nanoparticle diffusion estimates have been made by groups such as Shahid et al. using normalized fluorescence values [95, 145], further experimental data is needed to confirm these estimates for further 
quantification. This study illustrates a method for determining numerical concentrations of nanoparticles within tissue, using either 3D cell cultures or in vivo tissue. $[139,140]$ As discussed earlier, it is evident that two-layer nanoshells provide a clear advantage over PEGylated nanoshells. In some instances, threelayer nanoshells exhibited slightly more uptake into the solid tumors; this appeared to be the result of cancer-specific interactions. In conclusion, rather than PEGylating gold nanoshells, modifying the nanoshell with PC creates a viable two-layer nanoshell platform that consistently outperforms the current standard when measuring particle uptake. The additional modification of HDL also yielded particles capable of accumulating in 3D cell culture much better than PEGylated nanoparticles. As such, two- or three- layer SGN should be further considered for potential photothermal and targeted drug delivery therapies in the fight against cancer.

The work will be continued by examining the efficacy of two- and three- layer nanoshell system in photothermal applications. In addition, work is currently being done to investigate the potential for embedding drugs into the layers of the two- and three layer SGN and CGN for drug delivery. Our future plans include modifying these two- and three- layers nanoparticles with two chemotherapeutic agents, creating dual loaded nanoparticles. 


\section{SUMMARY AND CONCLUSIONS}

Nanotherapeutics offer a novel method for delivering chemotherapeutics to portions of tumor not previously accessible to drug alone, while decreasing toxicity and avoiding drug resistance. This project consisted of three main stages: development of nanoparticles, functionalization of nanoparticles, and determining nanoparticle diffusion with avascular tissue. While many groups have created PEGylated nanoparticles to increase circulation time and tumor uptake, we designed lipid encapsulated (also known as the two- or three- layered) nanoparticles to optimize their accumulation in tumor tissue. The lipid modifications consisted of phosphatidylcholine and high density lipoprotein. The microenvironment of solid tumors contains multiple drug hindering qualities that normally stop nanoparticles and drugs from diffusing distant from vasculature.

This study analyzed the accumulation of nanoparticles using a newly developed methodology consisting of a dark field microscopy with specialized hyperspectral imaging. Previous methods included the use of attached or entrapped dyes; however exact numerical data could not be obtained from this experimental method. Using the CytoViva Hyperspectral Imaging system, we were able to quantify the number of nanoparticles at different locations within 3D cell cultures. Using this data, we extrapolated the exact number of particles within the spheroid, while also analyzing the decreasing diffusion gradients of the nanoparticles from the periphery to center regions. Overall, this method provided significant improvements from past methodologies and can provide a deeper insight into nanoparticle and drug diffusion within solid tumors.

The results of this study suggest that lipid-coated nanoparticles (both two- and three-layer) exhibit superior penetration and diffusion capabilities compared to PEGylated nanoparticles. For this reason, we hypothesize that functionalization of nanoparticles with PC or HDL may be able to increase the nanoparticles concentration reaching cancerous tumors in vivo. These lipid functionalized nanoparticles will soon undergo drug attachment for in vitro toxicity testing before moving to in vivo studies. 


\section{REFERENCES}

1. Mei, Z., et al., The research on the anti-inflammatory activity and hepatotoxicity of triptolide-loaded solid lipid nanoparticle. Pharmacological Research, 2005. 51(4): p. 345-351.

2. Wong, C., et al., Multistage nanoparticle delivery system for deep penetration into tumor tissue. Proceedings of the National Academy of Sciences of the United States of America, 2011. 108(6): p. 2426-2431.

3. Society, A.C., Cancer Facts \& Figures 2013, 2013, American Cancer Society: Atlanta.

4. Martin Abeloff, J.A., John Niederhuber, Michael Kastan, W. Gillies McKenna, Abeloff's Clinical Oncology, ed. D. Meloni. Vol. 4. 2008, Philadelphia, PA: Churchill Livingstone Elsevier.

5. Minchinton, A.I. and I.F. Tannock, Drug penetration in solid tumours. Nat Rev Cancer, 2006. 6(8): p. 583-92.

6. Mueller-Klieser, W., Three-dimensional cell cultures: from molecular mechanisms to clinical applications. Am J Physiol, 1997. 273(4 Pt 1): p. C1109-23.

7. $\mathrm{Xu}$, J., et al., Combination of immunotherapy with anaerobic bacteria for immunogene therapy of solid tumours. Gene Therapy and Molecular Biology, 2009. 13(1): p. 36-52.

8. Maciej Mruglala, J.S., Tracy Batchelor, Delivering Anticancer Drugs to Brain Tumors, ed. D.L. Bruce Chabner. 2011, Philadelphia, PA: Lippincott Williams and Wilkins.

9. Evans, C.L., et al., Killing Hypoxic Cell Populations in a 3D Tumor Model with EtNBSPDT. Plos One, 2011. 6(8).

10. van de Ven, A.L., et al., Integrated intravital microscopy and mathematical modeling to optimize nanotherapeutics delivery to tumors. AIP Adv, 2012. 2(1): p. 11208.

11. Lee, J.J., et al., Predictive Modeling of In Vivo Response to Gemcitabine in Pancreatic Cancer. In Review, 2013.

12. Brown, J.M. and W.R. Wilson, Exploiting tumour hypoxia in cancer treatment. Nat Rev Cancer, 2004. 4(6): p. 437-47.

13. Sledge, G.W. and K.D. Miller, Exploiting the hallmarks of cancer: the future conquest of breast cancer. European Journal of Cancer, 2003. 39(12): p. 1668-1675.

14. Chabner, B.A., Cancer Chemotherapy and Biotherapy: Principles and Practice. 5 ed. 2011, Philadelphia, PA: Lippincott Williams \& Wilkins.

15. Katzung, B., Basic and Clinical Pharmacology. 10 ed. 2007: The McGraw-Hill Companies.

16. Page, R. and C. Takimoto, Principles of Chemotherapy, in Cancer Management: A Multidisciplinary Approach. 2007.

17. Davis, M.E., Z.G. Chen, and D.M. Shin, Nanoparticle therapeutics: an emerging treatment modality for cancer. Nat Rev Drug Discov, 2008. 7(9): p. 771-82.

18. Jain, R.K. and T. Stylianopoulos, Delivering nanomedicine to solid tumors. Nature Reviews Clinical Oncology, 2010. 7(11): p. 653-664.

19. Bissell, M.J. and D. Radisky, Putting tumours in context. Nature Reviews Cancer, 2001. 1(1): p. 46-54.

20. Tlsty, T.D. and L.M. Coussens, Tumor stroma and regulation of cancer development. Annual Review of Pathology-Mechanisms of Disease, 2006. 1(1): p. 119-150. 
21. Hirschhaeuser, F., et al., Multicellular tumor spheroids: An underestimated tool is catching up again. Journal of Biotechnology, 2010. 148(1): p. 3-15.

22. Vinci, M., et al., Advances in establishment and analysis of three-dimensional tumor spheroid-based functional assays for target validation and drug evaluation. Bmc Biology, 2012. 10.

23. Goodman, T.T., et al., Spatio-temporal modeling of nanoparticle delivery to multicellular tumor spheroids. Biotechnology and Bioengineering, 2008. 101(2): p. 388-399.

24. Cheng, G., et al., Micro-Environmental Mechanical Stress Controls Tumor Spheroid Size and Morphology by Suppressing Proliferation and Inducing Apoptosis in Cancer Cells. Plos One, 2009. 4(2).

25. Lasserre, J.P., et al., Effects of the Endocrine Disruptors Atrazine and PCB 153 on the Protein Expression of MCF-7 Human Cells. Journal of Proteome Research, 2009. 8(12): p. 5485-5496.

26. Klein, S.G., et al., Potential of coculture in vitro models to study inflammatory and sensitizing effects of particles on the lung. Toxicology in Vitro, 2011. 25(8): p. 15161534.

27. Xiong, Z.Y.a.H.-R., In vitro, Tissue-Based Models as a Replacement for Animal Models in Testing of Drugs at the Preclinical Stages, in Biomedical Tissue Culture, L.C.-

N.a.B.M. (Editor. 2012.

28. Derda, R., et al., Paper-supported 3D cell culture for tissue-based bioassays. Proceedings of the National Academy of Sciences of the United States of America, 2009. 106(44): p. 18457-18462.

29. Lee, J., et al., In vitro Toxicity Testing of Nanoparticles in 3D Cell Culture. Small, 2009. 5(10): p. 1213-1221.

30. Baumann, A., Early development of therapeutic biologics--pharmacokinetics. Curr Drug Metab, 2006. 7(1): p. 15-21.

31. Justice, B.A., N.A. Badr, and R.A. Felder, 3D cell culture opens new dimensions in cellbased assays. Drug Discovery Today, 2009. 14(1-2): p. 102-107.

32. Vertrees, R.A., et al., Cellular differentiation in three-dimensional lung cell cultures. Cancer Biol Ther, 2008. 7(3): p. 404-12.

33. Tseng, Q., et al., Spatial organization of the extracellular matrix regulates cell-cell junction positioning. Proc Natl Acad Sci U S A, 2012. 109(5): p. 1506-11.

34. Ghosh, S., et al., Three-dimensional culture of melanoma cells profoundly affects gene expression profile: a high density oligonucleotide array study. J Cell Physiol, 2005. 204(2): p. 522-31.

35. Weaver, V.M., et al., Reversion of the malignant phenotype of human breast cells in three-dimensional culture and in vivo by integrin blocking antibodies. Journal of Cell Biology, 1997. 137(1): p. 231-245.

36. Goodman, T.T., P.L. Olive, and S.H. Pun, Increased nanoparticle penetration in collagenase-treated multicellular spheroids. Int J Nanomedicine, 2007. 2(2): p. 265-74.

37. Kunz-Schughart, L., et al., The use of 3-D cultures for high-throughput screening: the multicellular spheroid model. J Biomol Screen, 2004. 9: p. 273 - 285.

38. Kim, J.W., W.J. Ho, and B.M. Wu, The role of the 3D environment in hypoxia-induced drug and apoptosis resistance. Anticancer Res, 2011. 31(10): p. 3237-45.

39. Sutherland, R.M., et al., Oxygenation and Differentiation in Multicellular Spheroids of Human-Colon Carcinoma. Cancer Research, 1986. 46(10): p. 5320-5329.

40. Alfaro-Moreno, E., et al., Co-cultures of multiple cell types mimic pulmonary cell communication in response to urban PM10. European Respiratory Journal, 2008. 32(5): p. 1184-1194. 
41. Sasaki, T., et al., Development of Multicellular Spheroids of Hela-Cells Cocultured with Fibroblasts and Their Response to X-Irradiation. Cancer Research, 1984. 44(1): p. 345351.

42. Duell, B.L., et al., Epithelial Cell Coculture Models for Studying Infectious Diseases: Benefits and Limitations. Journal of Biomedicine and Biotechnology, 2011.

43. Wang, A.Z., R. Langer, and O.C. Farokhzad, Nanoparticle Delivery of Cancer Drugs. Annual Review of Medicine, Vol 63, 2012. 63: p. 185-198.

44. Jokerst, J.V., et al., Nanoparticle PEGylation for imaging and therapy. Nanomedicine, 2011. 6(4): p. 715-728.

45. Cho, K., et al., Therapeutic nanoparticles for drug delivery in cancer. Clin Cancer Res, 2008. 14(5): p. 1310-6.

46. Kim, K., et al., Tumor-homing multifunctional nanoparticles for cancer theragnosis: Simultaneous diagnosis, drug delivery, and therapeutic monitoring. J Control Release, 2010. 146(2): p. 219-27.

47. Nie, S., Understanding and overcoming major barriers in cancer nanomedicine. Nanomedicine (Lond), 2010. 5(4): p. 523-8.

48. Hettiarachchi, K., et al., Controllable Microfluidic Synthesis of Multiphase DrugCarrying Lipospheres for Site-Targeted Therapy. Biotechnology Progress, 2009. 25(4): p. 938-945.

49. Wang, A.Z., R. Langer, and O.C. Farokhzad, Nanoparticle delivery of cancer drugs. Annu Rev Med, 2012. 63: p. 185-98.

50. Immordino, M.L., F. Dosio, and L. Cattel, Stealth liposomes: review of the basic science, rationale, and clinical applications, existing and potential. International Journal of Nanomedicine, 2006. 1(3): p. 297-315.

51. Nzai, J.M. and A. Proctor, Determination of phospholipids in vegetable oil by Fourier transform infrared spectroscopy. Journal of the American Oil Chemists Society, 1998. 75(10): p. 1281-1289.

52. Moon, S.Y., S. Tanaka, and T. Sekino, Crystal Growth of Thiol-Stabilized Gold Nanoparticles by Heat-Induced Coalescence. Nanoscale Research Letters, 2010. 5(5): p. 813-817.

53. Vogel, W., D.G. Duff, and A. Baiker, X-Ray Structure of a New Hydrosol of Gold Clusters. Langmuir, 1995. 11(2): p. 401-404.

54. Duff, D.G., et al., A New Hydrosol of Gold Clusters .2. A Comparison of Some Different Measurement Techniques. Langmuir, 1993. 9(9): p. 2310-2317.

55. Duff, D.G., A. Baiker, and P.P. Edwards, A New Hydrosol of Gold Clusters. Journal of the Chemical Society-Chemical Communications, 1993(1): p. 96-98.

56. Flores, J.C., et al., Variations in morphologies of silver nanoshells on silica spheres. Colloids and Surfaces a-Physicochemical and Engineering Aspects, 2008. 330(1): p. 8690.

57. Gref, R., Synthesis, Functionalization, and Surface Treatment of Nanoparticles, ed. M.-I. Baraton. 2003, California: American Scientific Publishers. 233-240.

58. Shuhua Yue, J.M.C.r.-M., Lesley S. Chaboub, Sophie A. Lelie`vre, Ji-Xin Cheng, LabelFree Analysis of Breast Tissue Polarity by Raman Imaging of Lipid Phase. Biophysical Journal, 2012. 102: p. 1215-1223.

59. van de Ven, A.L., et al., Integrated intravital microscopy and mathematical modeling to optimize nanotherapeutics delivery to tumors. Aip Advances, 2012. 2(1).

60. John P. Sinek, H.B.F., Balakrishnan Sivaraman, Vittorio Cristini, Mathematical and Computational Modeling of Nano Cancer Therapeutics. 2010.

61. Wong, E.W., P.E. Sheehan, and C.M. Lieber, Nanobeam mechanics: Elasticity, strength, and toughness of nanorods and nanotubes. Science, 1997. 277(5334): p. 1971-1975. 
62. Schmit, V.L., et al., Lab-on-a-Bubble: Synthesis, Characterization, and Evaluation of Buoyant Gold Nanoparticle-Coated Silica Spheres. Journal of the American Chemical Society, 2012. 134(1): p. 59-62.

63. Chen, Q., T. Kaneko, and R. Hatakeyama, Characterization of pulse-driven gas-liquid interfacial discharge plasmas and application to synthesis of gold nanoparticle-DNA encapsulated carbon nanotubes. Current Applied Physics, 2011. 11(5): p. S63-S66.

64. Seoudi, R., A.A. Fouda, and D.A. Elmenshawy, Synthesis, characterization and vibrational spectroscopic studies of different particle size of gold nanoparticle capped with polyvinylpyrrolidone. Physica B-Condensed Matter, 2010. 405(3): p. 906-911.

65. Kumar, V.K.R. and K.R. Gopidas, Synthesis and Characterization of Gold-NanoparticleCored Dendrimers Stabilized by Metal-Carbon Bonds. Chemistry-an Asian Journal, 2010. 5(4): p. 887-896.

66. Zheng, G.X., Y. Shao, and B. Xu, Synthesis and characterization of polyaniline coated gold nanoparticle and its primary application. Acta Chimica Sinica, 2006. 64(8): p. 733 737.

67. Zikich, D., et al., Synthesis and AFM Characterization of Poly $(d G)$-poly(dC)-gold Nanoparticle Conjugates. Bioconjugate Chemistry, 2010. 21(3): p. 544-547.

68. Glomm, W.R., et al., Synthesis and characterization of gold nanoparticle-functionalized ordered mesoporous materials. Journal of Dispersion Science and Technology, 2005. 26(6): p. 729-744.

69. Kumar, C.S.S.R., et al., Synthesis and characterization of S-Au interaction in gold nanoparticle bound polymeric beads. Journal of Nanoparticle Research, 2004. 6(4): p. 369-376.

70. Koizumi, S., S. Matsuda, and S. Ando, Synthesis, characterization, and optical properties of uniaxially drawn and gold nanoparticle dispersed fluorinated polyimide films. Journal of Photopolymer Science and Technology, 2002. 15(2): p. 231-236.

71. Chen, S.H. and K. Kimura, Synthesis and characterization of carboxylate-modified gold nanoparticle powders dispersible in water. Langmuir, 1999. 15(4): p. 1075-1082.

72. Vericat, C., et al., Self-assembled monolayers of thiols and dithiols on gold: new challenges for a well-known system. Chemical Society Reviews, 2010. 39(5): p. 18051834.

73. Rasch, M.R., et al., Hydrophobic gold nanoparticle self-assembly with phosphatidylcholine lipid: membrane-loaded and janus vesicles. Nano Lett, 2010. 10(9): p. 3733-9.

74. Zheng, G., et al., Rerouting lipoprotein nanoparticles to selected alternate receptors for the targeted delivery of cancer diagnostic and therapeutic agents. Proc Natl Acad Sci U S A, 2005. 102(49): p. 17757-62.

75. Oldenburg, S.J., et al., Nanoengineering of optical resonances. Chemical Physics Letters, 1998. 288(2-4): p. 243-247.

76. Habliston, D.L., et al., Early phorbol ester induced release of cell surface fibronectin: direct observation by photoelectron microscopy. Eur J Cell Biol, 1986. 41(2): p. 222-9.

77. Birrell, G.B., et al., Silver-enhanced colloidal gold as a cell surface marker for photoelectron microscopy. J Histochem Cytochem, 1986. 34(3): p. 339-45.

78. Danscher, G., Light and electron microscopic localization of silver in biological tissue. Histochemistry, 1981. 71(2): p. 177-86.

79. Danscher, G., Histochemical demonstration of heavy metals. A revised version of the sulphide silver method suitable for both light and electronmicroscopy. Histochemistry, 1981. 71(1): p. 1-16.

80. Thompson, M., et al., Paradoxical roles of serine racemase and d-serine in the G93A mSOD1 mouse model of amyotrophic lateral sclerosis. Journal of Neurochemistry, 2012. 120(4): p. 598-610. 
81. Namazi, M.R., Paradoxical exacerbation of psoriasis in AIDS: Proposed explanations including the potential roles of substance P and Gram-negative bacteria. Autoimmunity, 2004. 37(1): p. 67-71.

82. Klemer, A.R., et al., Cyanobacterial buoyancy regulation: The paradoxical roles of carbon. Journal of Phycology, 1996. 32(1): p. 47-53.

83. Oh, D.Y., et al., Increased Macrophage Migration Into Adipose Tissue in Obese Mice. Diabetes, 2012. 61(2): p. 346-354.

84. Nishihira, J., et al., Macrophage migration inhibitory factor (MIF): Its potential role in tumor growth and tumor-associated angiogenesis. Ann N Y Acad Sci, 2003. 995: p. 17182.

85. Fukuda, K., A. Kobayashi, and K. Watabe, The role of tumor-associated macrophage in tumor progression. Front Biosci (Schol Ed), 2012. 4: p. 787-98.

86. Dougherty, S.T., et al., Role of macrophage-colony-stimulating factor in regulating the accumulation and phenotype of tumor-associated macrophages. Cancer Immunol Immunother, 1997. 44(3): p. 165-72.

87. Pello, O.M., et al., Role of c-MYC in alternative activation of human macrophages and tumor-associated macrophage biology. Blood, 2012. 119(2): p. 411-21.

88. Arenberg, D.A., et al., Macrophage infiltration in human non-small-cell lung cancer: the role of CC chemokines. Cancer Immunol Immunother, 2000. 49(2): p. 63-70.

89. Du, K., H.L. Ma, and S. Muralidharan, Synthesis of gold nanoparticle clusters and their characterization by capillary electrophoresis, light scattering, and transmission electron microscopy. Abstracts of Papers of the American Chemical Society, 2006. 231.

90. Varney, M.L., et al., Monocyte/macrophage recruitment, activation and differentiation modulate interleukin-8 production: a paracrine role of tumor-associated macrophages in tumor angiogenesis. In Vivo, 2002. 16(6): p. 471-7.

91. Yuhas, J.M., et al., A simplified method for production and growth of multicellular tumor spheroids. Cancer Res, 1977. 37(10): p. 3639-43.

92. Lacko, A.G., et al., Prospects and challenges of the development of lipoprotein-based formulations for anti-cancer drugs. Expert Opinion on Drug Delivery, 2007. 4(6): p. 665675.

93. Maeda, H., et al., Tumor vascular permeability and the EPR effect in macromolecular therapeutics: a review. J Control Release, 2000. 65(1-2): p. 271-84.

94. Jain, R.K. and T. Stylianopoulos, Delivering nanomedicine to solid tumors. Nat Rev Clin Oncol, 2010. 7(11): p. 653-64.

95. Frieboes, H.B., et al., A computational model for predicting nanoparticle accumulation in tumor vasculature. PLoS One, 2013. 8(2): p. e56876.

96. Connor, E.E., et al., Gold nanoparticles are taken up by human cells but do not cause acute cytotoxicity. Small, 2005. 1(3): p. 325-7.

97. Xue, Z.G., et al., [Biotoxicology and biodynamics of silica nanoparticle]. Zhong Nan Da Xue Xue Bao Yi Xue Ban, 2006. 31(1): p. 6-8.

98. Brigger, I., C. Dubernet, and P. Couvreur, Nanoparticles in cancer therapy and diagnosis. Adv Drug Deliv Rev, 2002. 54(5): p. 631-51.

99. Drummond, D.C., et al., Pharmacokinetics and In Vivo Drug Release Rates in Liposomal Nanocarrier Development. Journal of Pharmaceutical Sciences, 2008. 97(11): p. 46964740.

100. Lasic, D.D., Sterically Stabilized Vesicles. Angewandte Chemie-International Edition in English, 1994. 33(17): p. 1685-1698.

101. van Vlerken, L.E., T.K. Vyas, and M.M. Amiji, Poly(ethylene glycol)-modified nanocarriers for tumor-targeted and intracellular delivery. Pharmaceutical Research, 2007. 24(8): p. 1405-1414. 
102. Tunnell, T.A.E.a.J.W., Gold Nanoshells in Biomedical Applications, in Nanomaterials for the Life Sciences, C. Kumar, Editor. 2009, Wiley-VCH.

103. Takahashi, H., et al., Modification of Gold Nanorods Using Phosphatidylcholine to Reduce Cytotoxicity. Langmuir, 2005. 22(1): p. 2-5.

104. Thaxton, C.S., et al., Templated Spherical High Density Lipoprotein Nanoparticles. Journal of the American Chemical Society, 2009. 131(4): p. 1384-+.

105. Rui, M., et al., Recombinant High Density Lipoprotein Nanoparticles for Target-Specific Delivery of siRNA. Pharm Res, 2012.

106. Huang, K., et al., Size-dependent localization and penetration of ultrasmall gold nanoparticles in cancer cells, multicellular spheroids, and tumors in vivo. ACS Nano, 2012. 6(5): p. 4483-93.

107. Kim, B., et al., Tuning payload delivery in tumour cylindroids using gold nanoparticles. Nat Nanotechnol, 2010. 5(6): p. 465-72.

108. Cabral, H., et al., Accumulation of sub-100 nm polymeric micelles in poorly permeable tumours depends on size. Nat Nanotechnol, 2011. 6(12): p. 815-23.

109. Frens, G., Controlled Nucleation for the Regulation of the Particle Size in Monodisperse Gold Solutions. Nature Physical Sciences, 1973. 241: p. 20-22.

110. Oldenburg, S.J., et al., Infrared extinction properties of gold nanoshells. Applied Physics Letters, 1999. 75(19): p. 2897-2899.

111. Kalele, S., et al., Nanoshell particles: synthesis, properties and applications. Current Science, 2006. 91(8): p. 1038-1052.

112. Caruso, F., et al., Multilayer assemblies of silica-encapsulated gold nanoparticles on decomposable colloid templates. Advanced Materials, 2001. 13(14): p. 1090-+.

113. Preston, T.C. and R. Signorell, Growth and Optical Properties of Gold Nanoshells Prior to the Formation of a Continuous Metallic Layer. Acs Nano, 2009. 3(11): p. 3696-3706.

114. Stober, W., A. Fink, and E. Bohn, Controlled Growth of Monodisperse Silica Spheres in Micron Size Range. Journal of Colloid and Interface Science, 1968. 21(1).

115. Duff, D.G., A. Baiker, and P.P. Edwards, A New Hydrosol of Gold Clusters .1. Formation and Particle-Size Variation. Langmuir, 1993. 9(9): p. 2301-2309.

116. Fidge, N.H., High density lipoprotein receptors, binding proteins, and ligands. J Lipid Res, 1999. 40(2): p. 187-201.

117. Shahzad, M.M.K., et al., Targeted Delivery of Small Interfering RNA Using Reconstituted High-Density Lipoprotein Nanoparticles. Neoplasia, 2011. 13(4): p. 309-U142.

118. Yen, J.C., F.J. Chang, and S. Chang, A new criterion for automatic multilevel thresholding. IEEE Trans Image Process, 1995. 4(3): p. 370-8.

119. Leung, K., Gold-polyethylene glycol nanoshells, in Molecular Imaging and Contrast Agent Database (MICAD). 2004: Bethesda (MD).

120. Thomas Maldiney, C.R., Johanne Seguin, Nicolas Wattier, Michel Bessodes, and Daniel Scherman, Effect of Core Diameter, Surface Coating, and PEG Chain Length on the Biodistribution of Persistent Luminescence Nanoparticles in Mice. ACS Nano, 2011. 5(2): p. 854-862.

121. Fatouros, D.G. and S.G. Antimisiaris, Effect of amphiphilic drugs on the stability and zeta-potential of their liposome formulations: A study with prednisolone, diazepam, and griseofulvin. Journal of Colloid and Interface Science, 2002. 251(2): p. 271-277.

122. Gu, X., et al., Preparation and characterization of a lovastatin-loaded protein-free nanostructured lipid carrier resembling high-density lipoprotein and evaluation of its targeting to foam cells. AAPS PharmSciTech, 2011. 12(4): p. 1200-8.

123. Krilov, D., et al., FT-IR spectroscopy of lipoproteins--a comparative study. Spectrochim Acta A Mol Biomol Spectrosc, 2009. 73(4): p. 701-6.

124. Gulmine, J.V., et al., Polyethylene characterization by FTIR. Polymer Testing, 2002. 21(5): p. 557-563. 
125. Wang, F., et al., FT-IR study of the interaction between phosphatidylcholine and bovine serum albumin. Acta Physico-Chimica Sinica, 2004. 20(10): p. 1186-1190.

126. Kumar, C.S.S.R., Mixed Metal Nanomaterials. 2009: John Wiley \& Sons.

127. D.R. Rothe, S.P.W., W.A. Heeschen, Imaging of Submicron Particulate in an Optical Flow Cell. Microsc Microanal, 200. 13(2).

128. Huang, K.Y., et al., Size-Dependent Localization and Penetration of Ultrasmall Gold Nanoparticles in Cancer Cells, Multicellular Spheroids, and Tumors in Vivo. Acs Nano, 2012. 6(5): p. 4483-4493.

129. Alkilany, A.M. and C.J. Murphy, Toxicity and cellular uptake of gold nanoparticles: what we have learned so far? Journal of Nanoparticle Research, 2010. 12(7): p. 23132333.

130. Estephan, Z.G., J.A. Jaber, and J.B. Schlenoff, Zwitterion-Stabilized Silica Nanoparticles: Toward Nonstick Nano. Langmuir, 2010. 26(22): p. 16884-16889.

131. Lal, S., S.E. Clare, and N.J. Halas, Nanoshell-Enabled Photothermal Cancer Therapy: Impending Clinical Impact. Accounts of Chemical Research, 2008. 41(12): p. 1842-1851.

132. Grosges, T., et al., Nanoshells for photothermal therapy: a Monte-Carlo based numerical study of their design tolerance. Biomedical Optics Express, 2011. 2(6): p. 1584-1596.

133. Yeung, T., et al., Membrane phosphatidylserine regulates surface charge and protein localization. Science, 2008. 319(5860): p. 210-213.

134. Goldenberg, N.M. and B.E. Steinberg, Surface Charge: A Key Determinant of Protein Localization and Function. Cancer Research, 2010. 70(4): p. 1277-1280.

135. Jeffrey D. Clogston, A.K.P., Characterization of Nanoparticles Intended for Drug Delivery. Methods in Molecular Biology 2011. 697: p. 63-70.

136. Elul, R., Fixed charge in the cell membrane. J Physiol, 1967. 189(3): p. 351-65.

137. Goel, R., et al., Biodistribution of TNF-alpha-coated gold nanoparticles in an in vivo model system. Nanomedicine, 2009. 4(4): p. 401-410.

138. Paciotti, G.F., et al., Colloidal gold: A novel nanoparticle vector for tumor directed drug delivery. Drug Delivery, 2004. 11(3): p. 169-183.

139. Lowery, A.R., et al., Immunonanoshells for targeted photothermal ablation of tumor cells. International Journal of Nanomedicine, 2006. 1(2): p. 149-154.

140. Gobin, A.M., et al., Near-infrared resonant nanoshells for combined optical imaging and photothermal cancer therapy. Nano Letters, 2007. 7(7): p. 1929-1934.

141. McNally, L.R., et al., KISS1 over-expression suppresses metastasis of pancreatic adenocarcinoma in a xenograft mouse model. Clinical \& Experimental Metastasis, 2010. 27(8): p. 591-600.

142. Kitamura, N., et al., High collagenolytic activity in spontaneously highly metastatic variants derived from a human pancreatic cancer cell line (SUIT-2) in nude mice. Clinical \& Experimental Metastasis, 2001. 18(7): p. 561-571.

143. Samlowski, W.E., et al., Effects of Supravital Fluorochromes Used to Analyze the Invivo Homing of Murine Lymphocytes on Cellular Function. Journal of Immunological Methods, 1991. 144(1): p. 101-115.

144. Alkilany, A.M. and C.J. Murphy, Toxicity and cellular uptake of gold nanoparticles: what we have learned so far? J Nanopart Res, 2010. 12(7): p. 2313-2333.

145. Mohammed Shahid, S.A., Minru Hwang, Pratik Patel, Elaine Yu, Charles Roth, Systematic Nanoparticle Diffusivity Estimation Using Multicellular Tumor Spheroid Model. IEEE, 2012. 12: p. 251-253. 


\section{CURRICULUM VITAE}

NAME: $\quad$ Christopher Gene England

ADDRESS: $\quad$ Center for Translational Research (CTR) 227A

505 S. Hancock Street

Louisville, KY 40202-1617

DOB: $\quad$ Elizabethtown, Kentucky - November 1, 1988

EDUCATION: B.S., Biochemistry and Molecular Biology

Bellarmine University - Louisville, KY

2007-2011

M.S., Pharmacology and Toxicology

University of Louisville

2011-Current

RESEARCH

EXPERIENCE: Concentration: Fungal Genetics

Dept. of Biochemistry and Molecular Biology

Bellarmine University - Louisville, KY

2009-2011

Concentration: Fungal Genetics

KBRIN Fellowship

University of Louisville

2009

Concentration: Nanotherapeutics for Oncology

Dept. of Pharmacology and Toxicology

University of Louisville

2011-current

AWARDS: $\quad$ First Place, Engineering Collaboration Award, Research Louisville Conference, 2012

First Year President of the Pharmacology and Toxicology Graduate Organization, 2011-2012

Interdisciplinary Program in the Biomedical Science Fellowship Recipient 2011-current

President of the Biochemistry and Molecular Biology Organization of Bellarmine University, 2008-2009

Kentucky Biomedical Research Infrastructure Network (KBRIN) Recipient, 2009

Monsignor Horrigan Scholar Recipient, 2007-2011 
PROFESSIONAL

SOCIETIES:

PUBLICATIONS:

PRESENTATIONS:

ABSTRACTS:

COURSEWORK:

SKILLS:
American Association for Cancer Research, 2013

World Molecular Imaging Society, 2013

Kentucky Academy of Science, 2013

American Chemical Society, 2007-2011

American Association for the Advancement of Science, 2007-2009

American Society for Biochemistry and Molecular Biology, 2008-2009

Christopher G. England, Guandong Zhang, Xinghua Sun, Dhru Patel, Lacey McNally, Victor van Berkel, Andre Gobin, and Hermann B. Frieboes. "Enhanced penetration into solid tumor tissue using two- and three-layered gold nanoparticles.” In Review, April 2013.

James Lee, Justin Huang, Christopher G. England, Lacey McNally, and Hermann B. Frieboes. "Predictive Modeling of In Vivo Response to Gemcitabine in Pancreatic Cancer.” In Review, March 2013.

Christopher G. England. "Nano-based therapeutics for the treatment of nonsmall cell lung cancer (NSCLC).” July 17, 2012. Department of Pharmacology and Toxicology, University of Louisville.

Christopher G. England. "Early detection of fungal infections in the clinic." April 12, 2011. Butler University Undergraduate Research Conference.

Christopher G. England, Justin Huang, Hermann Frieboes, and Lacey McNally. "Active targeting of EMPRINN receptors using S100A9 functionalized liposomes in melanoma and pancreatic cancers." World Molecular Imaging Conference, 2013.

Lacey McNally, Justin Huang, Christopher G. England, Hermann B. Frieboes. "Detection of Hypoxia in Orthotopic Pancreatic Tumors In Vivo Using Multispectral Optoacoustic Tomography.” World Molecular Imaging Conference, 2013.

Christopher G. England, Guandong Zhang, Xinghua Sun, Andre Gobin, and Hermann B. Frieboes. "Nanoparticle Penetration into Solid Tumors." James Graham Brown Cancer Center Conference, 2012.

Christopher G. England, Guandong Zhang, Xinghua Sun, Andre Gobin, and Hermann B. Frieboes "Optimization of Nanoparticle Diffusion into Solid Tumors.” Research Louisville, 2012.

Graduate Coursework in Biochemistry, Principles of Drug Action, Pharmacology and Toxicology, Research Methods, Cell Biology, Biostatistics, Grant Writing, Ethical Research Conduct, and Molecular Biology.

Cell Culture Work (monolayer and 3D cell cultures, along with co-cultures), Animal Work (including imaging using multispectral optoacustic tomography, bioluminescence, and x-ray), Nanoparticle Synthesis and Characterization (Organic and Inorganic Synthesis of Nanoparticles along with numerous 
characterization methods including SEM, STEM, CytoViva ${ }^{\circledR}$ Hyperspectral Imaging, Dark Field Microscopy). 